March 2017

\title{
"What to Buy When Forum Shopping? Analyzing Court Selection in Patent Litigation"
}

Fabian Gaessler and Yassine Lefouili 


\title{
What to Buy When Forum Shopping? Analyzing Court Selection in Patent Litigation
}

\author{
Fabian Gaessler ${ }^{a \dagger}$ \\ Yassine Lefouili ${ }^{b \ddagger}$ \\ ${ }^{a}$ Max Planck Institute for Innovation and Competition, Munich, Germany \\ ${ }^{b}$ Toulouse School of Economics, University of Toulouse Capitole, Toulouse, France
}

March 7, 2017

\begin{abstract}
This paper examines court selection by plaintiffs in patent litigation. We build a forum shopping model that provides a set of predictions regarding plaintiffs' court preferences, and the way these preferences depend on the market proximity between the plaintiff and the defendant. Then, using a rich dataset of patent litigation at German regional courts between 2003 and 2008, we estimate the determinants of court selection with alternative-specific conditional logit models. In line with our theoretical predictions, our empirical results show that plaintiffs prefer courts that have shorter proceedings, especially when they compete against the defendants they face. Further, we find negative effects of the plaintiff's, as well as the defendant's, distance to court on the plaintiff's court selection. Our empirical analysis also allows us to infer whether plaintiffs perceive a given court as more or less pro-patentee than another one.
\end{abstract}

KEYWORDS: Litigation, patents, forum shopping, Germany.

JEL Classification: K41, L38, O34

We acknowledge financial support for the creation of the dataset used in this research by the ZEW SEEK "Patent Litigation in Europe" project. We thank Max Ernicke, Peter Slowinski, and Alexander Wiese for advice on the legal aspects of this study. We are grateful to Stefan Bechtold, Timothy Bresnahan, Rosa Ferrer, Georg von Graevenitz, Bronwyn H. Hall, Dietmar Harhoff, Joachim Henkel, Steffen Juranek, Tobias Kretschmer, Margaret Kyle, Alan Marco, Geertrui van Overwalle, Kate Rockett and Jerry G. Thursby for their very helpful comments. We would also like to thank the participants at the 2nd International Workshop on the Economic Analysis of Litigation (Università di Torino), the 2nd International Meeting in Law \& Economics (Paris 2-Panthéon-Assas), the 6th ZEW/MaCCI Conference on the Economics of Innovation and Patenting, the 42nd Annual Conference of the EARIE 2015, the 10th Annual Conference of the EPIP Association, the 17th CEPR/JIE School on Applied Industrial Organization, and the workshop of the Intellectual Property and Markets for Technology Chair at Mines ParisTech.

${ }^{\dagger}$ Corresponding author. E-mail: fabian.gaessler@ip.mpg.de

†E-mail: yassine.lefouili@tse-fr.eu 


\section{Introduction}

To ensure local accessibility to justice, most judicial systems are characterized by the coexistence of multiple geographically dispersed entry courts. If a dispute fulfills the requirements for territorial jurisdiction at more than one of these courts, the plaintiff gains the option to conduct forum shopping; that is, to freely select the court of his choice to seek judicial relief. ${ }^{1}$ Particularly in patent litigation, forum shopping is considered common practice, since the infringing act, e.g., the manufacture or the sale of the infringing product, usually occurs at a national if not international scale (Moore, 2001b).

Forum shopping is considered a legitimate action authorized by law and repeatedly acknowledged by judges. Yet, in reference to the utterly disproportionate caseloads at some courts, such as the District Court in the Eastern District of Texas, critical views on forum shopping in patent litigation have recently gained considerable traction in the United States. Besides potential inefficiencies from undue case concentration, forum shopping is argued to aggravate the problems of abusive patent litigation by patent trolls, which frequently file cases at plaintiff-friendly, yet remote, locations (Cohen et al., 2016). To prevent further harm to the patent system, legal and economic scholars have recently urged both Congress and the Supreme Court for tighter restrictions on the plaintiff's choice of venue. ${ }^{2}$ Likewise, concerns about forum shopping are nothing new to legal debates in Europe. In particular, the potential abuse of forum shopping against small firms represents an essential aspect in the long-lasting debate on court structure and venue rules of the planned Unified Patent Court in Europe (Wadlow, 2015). ${ }^{3}$

This paper investigates theoretically and empirically the determinants of forum shopping in patent litigation. We build a model of forum shopping in which a patent holder can sue an alleged infringer before one of several courts. Courts are assumed to differ in the following dimensions: the litigation costs incurred by the patent holder and the alleged infringer (which may depend for instance on the distance between the parties and the court), the probability that the court rules in favor of the patent holder, and the length of the infringement proceeding. If the court finds that an infringement occurred, it hands down a decision regarding the damages for past infringement (i.e., the backward-looking remedies) and the future use of the infringing technology/product (i.e., the forward-looking remedies).

In the basic version of our model we find that, when choosing among courts, the patent holder values negatively his and the alleged infringer's litigation costs. We also show that the patent holder prefers a court where the proceeding is longer (shorter) if the expected backward-looking remedies are more (less) favorable to him than the expected forward-looking remedies. Further, we investi-

\footnotetext{
${ }^{1}$ Black's Law Dictionary defines forum shopping as "a litigant's practice of choosing the most favorable jurisdiction or court in which a claim might be heard." This definition emphasizes the litigation context, even though the notion of forum has been expanded to institutional certifiers, sponsors, and approvers (cf. Lerner and Tirole, 2006).

${ }^{2}$ For more details, see: the Letter to Congress and the Amicus Brief to the Supreme Court case TC Heartland LLC v. Kraft Food Brands Group LLC [last accessed: 31 January 2017].

${ }^{3}$ The Unified Patent Court as planned will consist of several spatially dispersed local and regional divisions all over Europe. While this ensures that plaintiffs gain local access to legal patent enforcement, the proceeding can be transferred to the central division (in Paris), for instance, in the case of a validity challenge.
} 
gate the way these effects are influenced by the market proximity between the patent holder and the alleged infringer. We find that the effect of litigation costs on the patent holder's court choice does not depend on market proximity while the effect of the proceeding length increases with market proximity. We then consider several extensions of our model in which we allow in turn for discounting, variable litigation costs, invalidity counterclaims, and settlement. Finally, to tie our theoretical model with our empirical study, we consider the special scenario in which forward-looking remedies are more favorable to the patent holder than backward-looking remedies, and derive a number of predictions that are robust across all the extensions.

We test these theoretical predictions using a comprehensive dataset on patent litigation in Germany - the jurisdiction that hears by far the largest share of patent litigation cases in Europe (Cremers et al., 2016a). The data cover all proceedings filed at three of the twelve available regional courts - namely, the regional courts in Düsseldorf ( $D U)$, Mannheim $(M A)$, and Munich $(M U)$ - between 2003 and 2008. These three courts account for approximately 80 to $90 \%$ of all patent infringement proceedings in Germany.

We first derive the plaintiff's ex ante expected length of proceeding from each court by accounting for the probabilities of two delaying events that may or may not occur during the proceeding. More precisely, we predict the alternative-specific likelihood of a requested expert opinion or a stay of the infringement proceeding due to a parallel validity challenge. As one source of variation in litigation costs, we capture the spatial distance between litigants and courts as a further factor determining court selection. To recover estimates of the plaintiffs' preferences for the three courts, we use alternative-specific conditional logit models. While our focus is on the effect of variations in trial duration and distance to court on the plaintiffs' court selection, we do not exclude court-specific differences in judicial decision making prima facie. In fact, the estimation models allow the inference of court-specific biases from residuals correlating with the economic value of the case.

In line with statements by practitioners, ${ }^{4}$ we find court-specific durations due to different likelihoods of delaying procedural events. It follows that courts exercise considerable discretion in case management and procedural options prior to a judgment on the merits. For instance, judges at the Düsseldorf regional court are significantly less likely to grant a stay or to request an expert opinion. So, even though ordinary proceedings take the longest at the Düsseldorf regional court due to its huge caseload, the low likelihood of procedural delays often gives it the lowest expected length of proceeding.

The results of the alternative-specific conditional logit models support the theoretical predictions on the determinants of court selection. The proceeding length has a negative effect on the plaintiff's court selection, especially when plaintiffs compete against the defendants they face. Further, the distance between a court and each of the parties has a significant negative effect on court selection, and the magnitude of this effect is more pronounced for the plaintiff's own distance to court than for the defendant's distance to court. We also find that the distance to court has a smaller effect on court choice for larger plaintiffs. Finally, we provide empirical support for a perceived anti-patentee bias

\footnotetext{
${ }^{4}$ See for instance Herr and Grunwald (2011); Pitz and Hermann (2005).
} 
associated with the Mannheim and Munich regional courts relative to the incumbent, the regional court in Düsseldorf.

The above-mentioned disparity between economic and litigious activity in some U.S. districts has triggered a steady stream of empirical legal literature that tries to link observable information on courts, such as average duration or win, settlement, and appeal rates, to their respective caseloads (see, e.g., McKelvie, 2007; Lemley, 2010; Lii, 2013). However, by relying on aggregated court level data, these papers cannot account for dispute-specific factors that may affect the plaintiff's preferences and fall short of fully explaining the popularity of particular venues.

In contrast to these studies, Atkinson et al. (2009) offer the first econometric study of forum shopping in patent litigation, which makes their paper the closest to ours in the literature. Our study, however, differs from theirs in two main respects. First, Atkinson et al. (2009) aim at assessing the extent of forum shopping in U.S. patent litigation before and after the establishment of the Court of Appeals for the Federal Circuit, while our objective is to study the determinants of forum shopping. Second, and relatedly, our theoretical model is richer than theirs since we allow for heterogeneity in the time that trials take in different courts, and include the market proximity between the plaintiff and the defendant as a key variable of the model.

The paper is structured as follows. Section 2 presents a model of forum shopping which provides predictions on the determinants of court selection. Section 3 describes the institutional framework of patent litigation in Germany. Section 4 provides details on the dataset and the construction of the variables. Section 5 contains the descriptive statistics. Section 6 presents an econometric analysis of the determinants of court selection. Section 7 contains the conclusion.

\section{A Model of Forum Shopping in Patent Litigation}

In this section we develop a model that depicts court selection as an optimization problem for the (patent-holding) plaintiff and use it to study the effects of a number of factors on that choice.

\subsection{Basic Setup}

Consider a dispute between a patent holder $P$ and an alleged infringer $D$. Assume that the alleged infringement occurs at $t=0$ and is detected by the patent holder at $t=T_{d} \geq 0$. The patent holder can then file a claim in one of several courts $j \in\{1,2, \ldots, J\}$. We denote $\tau^{j}$ the length of the infringement proceeding in court $j$ and assume that the patent holder's and alleged infringer's litigation costs (including opportunity costs), $C_{P}^{j}$ and $C_{D}^{j}$ respectively, depend on the court in which the case is filed. ${ }^{5}$ In the basic version of our model we suppose that litigation costs do not depend on the length of the proceeding. Without loss of generality, we can then assume that these costs are fully incurred when the case is filed at $t=T_{d}$.

\footnotetext{
${ }^{5}$ Litigation costs may depend, for instance, on the distance between the parties and the court.
} 
Suppose that the patent expires at $t=\bar{T}>T_{d}+\tau^{j}$ for all $j \in\{1,2, \ldots, J\}$, and that the patent holder (alleged infringer) is active in $N_{P} \geq 0\left(N_{D}>0\right)$ symmetric markets for which the patent in question is relevant. Denote $N_{P, D} \leq \min \left(N_{P}, N_{D}\right)$ the number of markets in which both parties are active. We assume that, in each of these markets, the patent holder makes a profit $\Pi_{P}$ per unit of time in the absence of the alleged infringer while he makes a profit $\Pi_{P}-L_{P}$ per unit of time in the alleged infringer's presence. Denote

$$
\gamma \equiv \frac{N_{P, D}}{N_{D}}
$$

This parameter can be interpreted as a measure of (patent-specific) market proximity between the patent holder and the alleged infringer. The polar case $\gamma=0(\gamma=1)$ means that there is no (perfect) overlap in product markets between the patent holder and the alleged infringer. ${ }^{6}$

Court $j \in\{1,2, \ldots, J\}$ finds that an infringement has occurred with probability $\theta^{j}$. When the court finds an infringement, it makes two decisions: it decides the amount of damages for past infringement, and whether to grant the plaintiff an injunction or allow the infringer to keep using (selling) the infringing technology (product) against the payment of "reasonable" royalties. ${ }^{7}$ If an infringement is found, then, in each of the $N_{D}-N_{P, D}$ markets in which the patent holder is not active, the court awards a reasonable royalty $\hat{R}$ per unit of time for past infringement and allows the alleged infringer to keep using the infringing technology (or selling the infringing product) if he pays the same royalty per unit of time to the patent holder (until the patent expires). ${ }^{8}$ In the remaining $N_{P, D}$ markets, when an infringement is found, the court awards damages per unit of time equal to the lost profits $L_{P}$ in each of the markets with probability $\alpha$, and a reasonable royalty $\tilde{R}$ with probability $1-\alpha$. Moreover, the court grants the patent holder an injunction that prevents the alleged infringer from being active in any of these $N_{D}-N_{P, D}$ markets with probability $\beta$, and allows the alleged infringer to continue using the infringing technology against the payment of $\tilde{R}$ per unit of time with probability $1-\beta$.

For the sake of simplicity, we assume that the infringer always finds it optimal to keep using the infringing technology against the payment of the reasonable royalty $\tilde{R}$ per unit of time. Also, we suppose that $L_{P}>\tilde{R}$, which captures the fact that lost profits are very often perceived as more favorable to the patent holder than reasonable royalties (see e.g., Friedman, 2016). In particular, in the U.S., "reasonable royalties exist as a floor or backstop for those who cannot prove that they have lost profits as a result of infringement" (Lemley, 2009). For the sake of exposition we focus on the case when the patent holder finds it optimal not to license its technology/product to a rival

\footnotetext{
${ }^{6}$ In particular, $\gamma=0$ if the patent holder is a non-practicing entity.

${ }^{7}$ When setting "reasonable" royalties, the court tries to guess the level of royalties that would have been agreed upon by the patent holder and the alleged infringer in the event of a hypothetical bilateral negotiation.

${ }^{8}$ Alternatively, we could assume that the court awards either reasonable royalties or an injunction in the markets where the patent holder is not active, and that the "reasonable" royalties are indeed the royalties that the parties would agree upon as part of a licensing agreement if the court grants an injunction. This amounts to assuming that the court does not make mistakes when setting "reasonable" royalties for the markets where the parties do not compete. Under this assumption, the patent holder is indifferent between being granted an injunction or reasonable royalties in those markets.
} 
against whom he competes in a product market, whenever an injunction is granted. ${ }^{9}$ Thus, in each market where the parties compete against each other, the patent holder's post-judgment benefit (per unit of time) from an infringement decision is $L_{P}$ if an injunction is granted, and $\tilde{R}$ otherwise. This, combined with the assumption $L_{P}>\tilde{R}$, implies that the patent holder always prefers an injunction to reasonable royalties. ${ }^{10}$

We denote $\lambda \in[0,1]$ the share of the winner's litigation costs borne by the loser. The polar case $\lambda=0(\lambda=1)$ corresponds to the so-called American (British) rule of cost allocation. Finally, for the sake of exposition, we assume for now that there is no discounting.

\subsection{Patent Holder's Choice}

A patent holder who finds it optimal to sue the alleged infringer chooses court

$$
j^{*}=\underset{1 \leq j \leq J}{\arg \max } V\left(C_{P}^{j}, C_{D}^{j}, \theta^{j}, \tau^{j}\right)
$$

where

$$
\begin{aligned}
V\left(C_{P}, C_{D}, \theta, \tau\right) \equiv & \theta N_{D}\left\{\gamma\left[\left(T_{d}+\tau\right)\left(\alpha L_{P}+(1-\alpha) \tilde{R}\right)+\left(\bar{T}-T_{d}-\tau\right)\left(\beta L_{P}+(1-\beta) \tilde{R}\right)\right]+(1-\gamma) \bar{T} \hat{R}\right\} \\
& -\theta(1-\lambda) C_{P}-(1-\theta)\left(C_{P}+\lambda C_{D}\right)
\end{aligned}
$$

is the patent holder's expected (net) gain from suing the alleged infringer before a court when the parties' litigation costs are $C_{P}$ and $C_{D}$, the probability that an infringement is found is $\theta$, and the length of the infringement proceeding is $\tau$.

To understand the determinants of the patent holder's choice we need to study how the value function $V\left(C_{P}, C_{D}, \theta, \tau\right)$ depends on its arguments. It is straightforward that

$$
\frac{\partial V}{\partial \theta}>0
$$

and

$$
\frac{\partial V}{\partial C_{P}} \leq \frac{\partial V}{\partial C_{D}} \leq 0
$$

with the latter inequality being strict whenever $\lambda>0$. Moreover, the effect of the trial's length $\tau$ is given by:

$$
\begin{aligned}
\frac{\partial V}{\partial \tau} & =\theta N_{P, D}\left[\left(\alpha L_{P}+(1-\alpha) \tilde{R}\right)-\left(\beta L_{P}+(1-\beta) \tilde{R}\right)\right] \\
& =\theta N_{D} \gamma(\alpha-\beta)\left(L_{P}-\tilde{R}\right)
\end{aligned}
$$

\footnotetext{
${ }^{9}$ However, all our results qualitatively hold in the alternative scenario where the patent holder finds it optimal to license its technology/product to a competing infringer.

${ }^{10}$ Note that this result is strengthened if the patent holder finds it optimal to license its technology/product when granted an injunction.
} 
This implies that

$$
\frac{\partial V}{\partial \tau}=0
$$

if there is no overlap between the parties in product markets (i.e., $\gamma=0$ ), and

$$
\frac{\partial V}{\partial \tau} \gtrless 0 \Longleftrightarrow \alpha \gtrless \beta
$$

if the parties compete against each other in at least one product market (i.e., $\gamma>0$ ). This statement captures a more general insight: holding everything else equal, the patent holder prefers a court where the length of the proceeding is greater (smaller) if the expected backward-looking ${ }^{11}$ remedies, i.e., the damages for past infringement, are more (less) favorable than the expected forward-looking remedies, i.e., those resulting from the court's decision regarding future use of the infringing technology/product. In our model, the expected backward-looking and forward-looking remedies are the same in the markets where the patent holder does not compete against the alleged infringer. This explains why the patent holder is indifferent regarding the length of the proceeding when he does not compete against the alleged infringer in any product market. However, in each of the markets where the parties compete against each other, the expected backward-looking remedies per unit of time are given by $\alpha L_{P}+(1-\alpha) \tilde{R}$, while the corresponding expected forward-looking remedies are $\beta L_{P}+(1-\beta) \tilde{R}$. This, combined with the fact that $L_{P}>\tilde{R}$, implies that, in our model, the comparison of backward-looking and forward-looking remedies in the markets where the two parties compete reduces to the comparison of $\alpha$ and $\beta$.

We summarize these results in the following proposition.

Proposition 1 Everything else equal, the patent holder

- prefers a court where the probability that an infringement is found is higher;

- prefers a court that induces less litigation costs for him;

- prefers a court that induces less litigation costs for the alleged infringer if part or all of the winner's litigation costs are borne by the loser;

- prefers a court where the proceeding is longer (shorter) if the expected backward-looking remedies are more (less) favorable to the patent holder than the expected forward-looking remedies.

The relative size of backward-looking remedies with respect to forward-looking remedies depends on the jurisdiction one considers. For instance, in Germany, the latter are more favorable than the former (i.e., $\alpha \leq \beta$ ) because injunctions are automatically granted to a patent holder that prevails in an infringement suit (i.e., $\beta=1$ ). In the U.S., however, it is unclear how backward-looking remedies compare to forward-looking remedies. On the one hand, the US Supreme Court's landmark 2006 decision in the eBay case imposed restrictive conditions under which an injunction can be

\footnotetext{
${ }^{11}$ We borrow this term from Shapiro (2017) who compares the performance of (permanent) injunctions and reasonable royalties as forward-looking remedies in patent infringement cases. See also Schankerman and Scotchmer (2001) and Shapiro (2016) for a comparison of injunctions and reasonable royalties.
} 
granted, which implies that $\beta<1$. On the other hand, lost profits are awarded only if the conditions of the so-called Panduit test are met, ${ }^{12}$ which implies that $\alpha<1$.

\subsection{Impact of Market Proximity}

We now investigate the effect of market proximity on the magnitude of the effects of litigation costs and proceeding length on the patent holder's expected gain from suing the alleged infringer in a given court. We have

$$
\frac{\partial^{2} V}{\partial \gamma \partial C_{P}}=\frac{\partial^{2} V}{\partial \gamma \partial C_{D}}=0
$$

which means that the marginal effect of each party's litigation costs on the patent holder's gain from suing the alleged infringer does not depend on the market proximity between the parties. Moreover, it is straightforward that the absolute value of $\partial V / \partial \tau$ increases in $\gamma$. Therefore, we get the following result:

Proposition 2 (i) The effect of litigation costs on the patent holder's expected gain from suing the alleged infringer does not depend on market proximity.

(ii) The effect of the proceeding length on the patent holder's expected gain from suing the alleged infringer increases with market proximity.

Part (i) of this proposition follows from the fact that the effect of litigation costs on the gain from litigation in a given market does not depend on whether the parties compete or not in that market. Part (ii) shows that the magnitude of the effect of the proceeding length increases with market proximity regardless of the sign of that effect. The reason behind this is that the effect of the proceeding length is driven by the difference between backward-looking and forward-looking remedies, and this difference exists only in markets in which both parties are active. ${ }^{13}$

\subsection{Extensions}

In this section we consider a number of extensions of our basic setup and assess the robustness of our results.

\footnotetext{
${ }^{12}$ In order to recover lost sales, the patent holder must establish four things: a demand for the patented product, that there was no acceptable non-infringing substitutes, a manufacturing capability to supply the market, and the profit that would have been made on lost sales.

${ }^{13}$ Note that this result would remain true in a model where there would be a difference between backwardlooking and forward-looking remedies in the markets in which the patent holder is not active, as long as this difference is smaller than its counterpart in markets where the patent holder is active. This is likely to be true in practice because the discrepancies between backward-looking and forward-looking remedies are generally related to the fact that courts underestimate (or ignore) the impact of the infringement on the patent holder's market profits when they set "reasonable" royalties.
} 


\section{Discounting}

Assume that the patent holder discounts future payoffs and denote $r$ the interest rate. For the sake of notational convenience, suppose that $T_{d}=0$ (i.e., the alleged infringed is detected immediately). Then, the patent holder's expected payoff $V\left(C_{P}, C_{D}, \theta, \tau\right)$ from suing the alleged infringer (discounted to $t=0$ ) is given by

$$
\begin{aligned}
& \theta N_{D}\left\{\gamma\left[\int_{0}^{\tau}\left(\alpha L_{P}+(1-\alpha) \tilde{R}\right) e^{-r t} d t+\int_{\tau}^{\bar{T}}\left(\beta L_{P}+(1-\beta) \tilde{R}\right) e^{-r t} d t\right]+(1-\gamma) \int_{0}^{\bar{T}} \hat{R} e^{-r t} d t\right\} \\
& -\theta(1-\lambda) C_{P}-(1-\theta)\left(C_{P}+\lambda C_{D}\right) \\
= & \theta N_{D}\left\{\gamma\left[\frac{1-e^{-r \tau}}{r}\left(\alpha L_{P}+(1-\alpha) \tilde{R}\right)+\frac{e^{-r \tau}-e^{-r \bar{T}}}{r}\left(\beta L_{P}+(1-\beta) \tilde{R}\right)\right]+(1-\gamma) \frac{\left.1-e^{-r \bar{T}} \hat{R}\right\}}{r} \hat{R}\right. \\
& -\theta(1-\lambda) C_{P}-(1-\theta)\left(C_{P}+\lambda C_{D}\right)
\end{aligned}
$$

It is still the case that $V\left(C_{P}, C_{D}, \theta, \tau\right)$ is decreasing in $C_{P}$, weakly decreasing in $C_{D}$, and increasing in $\theta$. Moreover, $\partial V / \partial \tau$ still has the same sign as $\gamma(\alpha-\beta)$ and its absolute value is increasing in $\gamma$. Finally, $\partial V / \partial C_{P}$ and $\partial V / \partial C_{D}$ do not depend on $\gamma$. Therefore, Propositions 1 and 2 remain true in the presence of discounting.

\section{Variable Litigation Costs}

Assume now that the litigation costs incurred by the patent holder when suing the alleged infringer in court $k$ are given by $C_{P}^{j}+c_{P}^{j} \tau^{j}$ and that the alleged infringer's litigation costs are $C_{D}^{j}+c_{D}^{j} \tau^{j}$. In this scenario, the patent holder's expected gain from suing the alleged infringer before court $j$ is $V\left(C_{P}^{j}, C_{D}^{j}, c_{P}^{j}, c_{D}^{j}, \theta^{j}, \tau^{j}\right)$ where

$$
\begin{aligned}
V\left(C_{P}, C_{D}, c_{P}, c_{D}, \theta, \tau\right) \equiv & \theta N_{D} \gamma\left[\left(T_{d}+\tau\right)\left(\alpha L_{P}+(1-\alpha) \tilde{R}\right)+\left(\bar{T}-T_{d}-\tau\right)\left(\beta L_{P}+(1-\beta) \tilde{R}\right)\right] \\
& +\theta N_{D}(1-\gamma) \bar{T} \hat{R}-\theta(1-\lambda)\left(C_{P}+c_{P} \tau\right)-(1-\theta)\left(C_{P}+c_{P} \tau+\lambda\left(C_{D}+c_{D} \tau\right)\right) .
\end{aligned}
$$

We now have

$$
\frac{\partial V}{\partial \tau}=\theta N_{D} \gamma(\alpha-\beta)\left(L_{P}-\tilde{R}\right)-\theta(1-\lambda) c_{P}-(1-\theta)\left(c_{P}+\lambda c_{D}\right)
$$

Then, all the statements in Proposition 1 still hold except for the last one which should be modified as follows: if the expected forward-looking remedies are sufficiently more favorable to the patent holder than the expected backward-looking remedies, then the patent holder prefers a court where the proceeding is longer; otherwise, he prefers a court where the proceeding is shorter. In particular, the latter holds whenever the expected backward-looking remedies are less favorable than the expected forward-looking remedies (i.e., $\alpha \leq \beta$ ).

Part (i) of Proposition 2 also remains true in this context. Part (ii), however, must be modified. Note that the effect of the proceeding length on the patent holder's expected gain from suing 
the alleged infringer increases with market proximity if $\frac{\partial^{2} V}{\partial \gamma \partial \tau}$ and $\frac{\partial V}{\partial \tau}$ have the same sign. This is equivalent to

$$
\frac{\frac{\partial^{2} V}{\partial \gamma \partial \tau}}{\frac{\partial V}{\partial \tau}}=\frac{\theta N_{D}(\alpha-\beta)\left(L_{P}-\tilde{R}\right)}{\theta N_{D} \gamma(\alpha-\beta)\left(L_{P}-\tilde{R}\right)-\theta(1-\lambda) c_{P}-(1-\theta)\left(c_{P}+\lambda c_{D}\right)}>0
$$

whenever the denominator is different from zero. Therefore, in the current extension, market proximity still positively affects the magnitude of the effect of the proceeding length on the patent holder's expected gain whenever the expected backward-looking remedies are less favorable than the expected forward-looking remedies (i.e., $\alpha \leq \beta$ ).

\section{Invalidity Counterclaim}

In this extension we assume that the patent's validity is uncertain ${ }^{14}$ and that the alleged infringer files an invalidity counterclaim. ${ }^{15}$

Non-Bifurcated System In a non-bifurcated litigation system, i.e., a system in which the issues of validity and infringement are decided simultaneously by the same court, all the results of the basic model extend in a straightforward way: we just need to replace the parameter $\theta^{j}$ with the parameter $\mu^{j} \theta^{j}$ where $\mu^{j}$ is the probability that the patent's validity is upheld by court $j$.

Bifurcated System In a non-bifurcated system the issues of validity and infringement are decided by two different courts. In that scenario, we suppose that there is only one court that examines the patent's validity (otherwise we would have an additional type of forum shopping) and that the probability that this court upholds the patent is $\mu$. Also, for the sake of simplicity, let us assume that the alleged infringer always finds it optimal to challenge the patent's validity when sued for infringement and that the invalidity counterclaim is filed immediately after the infringement claim is filed.

If the length of the validity proceeding $\tau^{\prime}$ is less than or equal to the length of the infringement proceeding $\tau^{j}$ then the analysis is formally equivalent to the one under a non-bifurcated system: again, we just need to replace the parameter $\theta^{j}$ by $\mu \theta^{j}$. However, if $\tau^{\prime}>\tau^{j}$ then there is a "gap" during which the patent is enforced although it is invalidated later. Following Cremers et al. (2016b) we model the effect of this gap in a reduced-form way by assuming that the patent holder derives an expected benefit $b \geq 0$ per unit of time during that period of time. Then, the patent holder's

\footnotetext{
${ }^{14}$ See e.g., Crampes and Langinier (2002), Farrell and Shapiro (2008), and Encaoua and Lefouili (2009) for models of patent litigation/settlement with potentially invalid patent rights.

${ }^{15}$ If the patent's validity is uncertain but the alleged infringer does not file an invalidity counterclaim then it is straightforward that the results in the basic model carry over.
} 
expected payoff function is

$$
\begin{aligned}
V\left(C_{P}, C_{D}, \theta, \tau\right)= & \mu \theta N_{D} \gamma\left[\left(T_{d}+\tau\right)\left(\alpha L_{P}+(1-\alpha) \tilde{R}\right)+\left(\bar{T}-T_{d}-\tau\right)\left(\beta L_{P}+(1-\beta) \tilde{R}\right)\right] \\
& +\mu \theta N_{D}(1-\gamma) \bar{T} \hat{R}+(1-\mu) \theta b\left(\tau^{\prime}-\tau\right)-\theta(1-\lambda) C_{P}-(1-\theta)\left(C_{P}+\lambda C_{D}\right)
\end{aligned}
$$

This payoff function is still decreasing in $C_{P}$, weakly decreasing in $C_{D}$, and increasing in $\theta$. However,

$$
\frac{\partial V}{\partial \tau}=\mu \theta N_{D} \gamma(\alpha-\beta)\left(L_{P}-\tilde{R}\right)-(1-\mu) \theta b
$$

There is now a new effect, captured by the negative term $-(1-\mu) \theta b$, that makes shorter infringement proceedings more attractive than in the basic model: a decrease in the length of the infringement proceeding leads to an increase in the length of the period during which an invalid patent is enforced. With this new effect, the patent holder still prefers courts with shorter proceedings if backward-looking remedies are less favorable than forward-looking remedies to the patent holder (i.e., $\alpha \leq \beta$ ), but also prefers them if backward-looking remedies are moderately more favorable than forward-looking remedies.

Furthermore, part (i) of Proposition 2 still holds. Part (ii) still holds too if

$$
\frac{\frac{\partial^{2} V}{\partial \gamma \partial \tau}}{\frac{\partial V}{\partial \tau}}=\frac{\mu \theta N_{D}(\alpha-\beta)\left(L_{P}-\tilde{R}\right)}{\mu \theta N_{D} \gamma(\alpha-\beta)\left(L_{P}-\tilde{R}\right)-(1-\mu) \theta b}>0
$$

which is the case if backward-looking remedies are less favorable than forward-looking remedies $(\alpha \leq \beta)$ or $b$ is not too large. If $\alpha>\beta$ and $b$ is large enough, then the effect of the infringement proceeding's length on the patent holder's expected gain from suing the alleged infringer decreases with market proximity.

\section{Scope of Infringement}

Denoting $\sigma$ a measure of the scope of infringement, it is natural to assume that $L_{P}=L_{P}(\sigma), \tilde{R}=$ $\tilde{R}(\sigma)$ and $\hat{R}=\hat{R}(\sigma)$ are increasing functions of $\sigma$. From

$$
\begin{aligned}
V\left(C_{P}, C_{D}, \theta, \tau, \sigma\right) \equiv & \theta N_{D} \gamma\left[\left(T_{d}+\tau\right)\left(\alpha L_{P}+(1-\alpha) \tilde{R}(\sigma)\right)+\left(\bar{T}-T_{d}-\tau\right)\left(\beta L_{P}+(1-\beta) \tilde{R}(\sigma)\right)\right] \\
& +\theta N_{D}(1-\gamma) \bar{T} R(\sigma)-\theta(1-\lambda) C_{P}-(1-\theta)\left(C_{P}+\lambda C_{D}\right)
\end{aligned}
$$

it follows that

$$
\frac{\partial^{2} V}{\partial \sigma \partial \theta}>0
$$

Hence, intuitively, the patent holder tends to favor a pro-patentee court more if the scope of infringement is higher. 


\section{Settlement}

In this extension we assume that the alleged infringer has private information on the probability of infringement (at each given court) and that the parties can sign a settlement agreement. The analysis in the baseline model remains valid if the settlement attempt takes place before the patent holder files a claim in a court, i.e., if the parties engage in pre-trial settlement. This holds because the court choice is made by the patent holder only in the event where settlement fails. The conclusions of the model also remain true if the parties try to settle after the patent holder files a claim in a given court but the patent holder cannot commit not to go to another court if settlement fails. Given that the cost of filing a claim accounts generally for a very small share of total litigation costs, we believe that this credibility problem is indeed relevant in practice and complicates the strategic use of court choice by the patent holder to secure a more favorable settlement.

\subsection{Application}

Let us consider here the special scenario in which forward-looking remedies are more favorable than backward-looking remedies (i.e., $\alpha \leq \beta$ ) and the loser pays at least part of the winner's litigation costs (i.e., $\lambda>0$ ). This scenario applies for instance in the jurisdiction we consider in our empirical analysis, Germany, where injunctions are automatically granted and a particular form of the loserpay rule applies. ${ }^{16}$ To tie further the predictions of our model with our empirical analysis we also make the assumption that a party's litigation costs are increasing in the distance separating it from the court where the case is heard, ${ }^{17}$ and focus on the distinction between litigants that do not compete against each other in any product market (i.e, $\gamma=0$ ) and litigants that compete against each other in at least one product market (i.e., $\gamma>0$ ) .

We can now derive a set of theoretical predictions that are robust across all the considered extensions ${ }^{18}$ and that can be tested with our data on litigation in Germany:

Prediction 1: Everything else equal, the patent holder (strictly) prefers a court that is closer to him.

Prediction 2: Everything else equal, the patent holder (strictly) prefers a court that is closer to the alleged infringer.

Prediction 3: The effect of the distance between the patent holder and a court on the plaintiff's court choice is larger than the effect of the distance between the alleged infringer and a court.

Prediction 4: Everything else equal, the patent holder (weakly) prefers a court where the proceeding is shorter. Moreover, the effect of the proceeding length on court choice is larger if the

\footnotetext{
${ }^{16}$ The precise cost allocation rule in Germany in discussed in the empirical section.

${ }^{17}$ The burden to litigate before a distant and unfamiliar court is an established consideration in the legal discussion on adjudicatory jurisdiction (cf. von Mehren, 1983). This burden is even higher for foreign firms as they are more likely to lack relevant experience and legal representation in the domestic judiciary, and often face additional communication and translation expenses (Lanjouw and Schankerman, 2001).

${ }^{18}$ Note that conditions (2.1) and (2.2) are always satisfied when $\alpha \leq \beta$. Condition (2.2) is relevant in the case of Germany because the German patent litigation system is bifurcated.
} 
plaintiff and the defendant compete against each other in at least one product market.

Prediction 5: The effect of the distance between any of the two parties and a court on the patent holder's gain from litigation does not depend on whether the patent holder and the alleged infringer are competitors or not.

Note also that we can use the theoretical prediction that the patent holder favors a pro-patentee court more if the scope of infringement is higher to infer from our data which court is considered more pro-patentee. This requires, however, to have an observable measure of the scope of infringement. As will be argued in detail in the empirical section, the "litigation value" used in German courts is essentially a measure of the scope of infringement.

\section{Patent Litigation in Germany}

\subsection{Court Structure}

Germany's court structure follows a continental style civil law system with a federal structure, which differentiates courts by both specialism and territory (cf. Cabrillo and Fitzpatrick, 2008). Courts of general jurisdiction have authority over all civil disputes, including patent litigation, and constitute a four-tier hierarchy. The channel for patent litigation cases starts with the action filed at second-tier regional courts (Landgerichte $-L G$ ). ${ }^{19}$

The number of regional courts with subject matter jurisdiction to hear patent litigation cases has been consolidated by the federal states, and currently stands at twelve (cf. Figure A- 1 in the Appendix). ${ }^{20}$ The plaintiff can file his action at the jurisdiction of either the defendant's main place of business, residence, or the place of infringement. If the infringing act comprises a Germany-wide offer ${ }^{21}$ of the infringing embodiment, the plaintiff gains the option to file his action at any of the twelve regional courts. In reality, the plaintiff is usually unrestricted in his choice. ${ }^{22}$

Each of the regional courts has at least one chamber primarily designated to patent litigation cases. ${ }^{23}$ A case is heard by a panel of three judges: one presiding and two sitting judges, all fully trained legal professionals. The plaintiff's claims must ground on a German patent $(D E)$ or a Eu-

\footnotetext{
${ }^{19}$ Decisions by the regional courts can be appealed before their respective higher regional court (Oberlandesgericht - OLG; in Berlin: Kammergericht), and may be brought before the Patent Division of the Federal Court of Justice (Bundesgerichtshof - BGH) for a further appeal, limited to matters of law only.

${ }^{20}$ These are the regional courts in Berlin, Braunschweig, Düsseldorf, Erfurt, Frankfurt, Hamburg, Leipzig, Magdeburg, Mannheim, Munich, Nuremberg-Furth, and Saarbrücken.

${ }^{21}$ This includes, for instance, advertising on the internet or in national publications.

${ }^{22}$ Unlike in the U.S., the defendant has no legal means to demand a transfer if the current court's requirements for territorial jurisdiction are met. Furthermore, the prior request for a declaratory judgment by the alleged infringer does not restrict the patent holder from subsequently filing his action at another suitable regional court. Rather, the request for declaratory judgment will be terminated and become part of the proceeding initiated by the patent holder.

${ }^{23}$ If the regional court has more than one chamber designated to hearing patent cases, the internal assignment of the filed action follows a transparent system specified in the court's case assignment plan. However, this system is unpredictable ex ante for the plaintiff.
} 
ropean patent granted with effect for Germany $(E P)$. The decision on infringement is enforceable throughout Germany.

\subsection{The Infringement Proceeding}

In contrast to patent litigation proceedings in other systems, proceedings on infringement before German regional courts are streamlined and have a clear, almost rigid, outline that allows little divergence from the ordinary structure. ${ }^{24}$ Judges usually refrain from stepped actions and instead initiate separate, adjacent proceedings for additional claims (cf. Figure A-2 in the Appendix). In the following, we will focus on the heart of a patent dispute - the infringement main proceeding.

\section{Structure of the Main Proceeding}

The infringement main proceeding is initiated by the plaintiff through filing the infringement action, in which he states his claims and estimates the litigation value, i.e., the scope of infringement (cf. Figure A-3 in the Appendix). Several forms of legal relief are available to the plaintiff. He may claim for an order to cease and desist from further infringement, for recall and destruction of the infringing goods, for information and rendering of account to identify distribution channels and calculate damages, for compensation of damages, as well as for notification of judgment. ${ }^{25}$

Subject to the court's practice, the litigants meet in a so-called early oral hearing, where deadlines for the further exchange of statements and the date for the main oral hearing are scheduled. Alternatively, the court gives notice in written form. Subsequently, the alleged infringer states her defense. In contrast to other systems, the alleged infringer cannot challenge the patent's validity in the infringement proceeding.

Prior to the main oral hearing, each party exchanges between one and two written statements specifying their own reasoning and countering the opposing party's arguments. The main oral hearing takes place roughly between six to twelve months after the action was filed, primarily depending on the court's docket. The court gives written notice to the litigants about its judgment usually four to eight weeks after the main oral hearing, concluding the proceeding in the first instance. With every judgment, there is a ruling on the costs of the proceeding. In contrast to the U.S., the winning litigant can demand the reimbursement of legal costs from the opponent. ${ }^{26}$

Infringement proceedings mainly diverge from the structure of ordinary proceedings as described above, if the court decides, during or right after the main oral hearing, to either stay the proceeding due to a parallel invalidity proceeding or demand further evidence in the form of an expert opinion. Both events will considerably delay the judgment on infringement.

\footnotetext{
${ }^{24}$ See Harguth and Carlson (2011) for an elaborate description of the German patent infringement proceeding.

${ }^{25}$ The entitlement to these remedies is independent of the plaintiff's own status as a practicing or nonpracticing entity.

${ }^{26}$ Legal costs include court fees, attorney-at-law as well as patent attorney fees and to some extent further expenses, such as travel or translation costs. Attorneys may charge their clients significantly higher fees than those eligible for reimbursement, thus legal costs are not always entirely shifted to one party.
} 


\section{Expert Opinion}

Construing patent claims and analyzing the composition of the allegedly infringing embodiment requires a sophisticated understanding of the respective technology from the presiding judge. Case law has established that judges experienced in dealing with patent infringement cases can answer technical questions independently if they have the necessary expertise. However, if the facts are technically complex and the judges lack the technical expertise to decide on infringement, they must request an expert opinion. The decision to request an expert opinion is at the judges' discretion; however, judges are advised to rely on experts if their own expertise is insufficient. ${ }^{27}$ The litigants have very limited influence on the request for an expert opinion. The call for an expert by the judge can be neither ordered nor challenged by the litigants. The experts appointed to state their opinion for the assessment of technical questions in written form are usually professors or patent attorneys with a significant expertise in the respective field of technology. The request for an expert opinion usually delays a decision on infringement by about two years (Kühnen, 2012).

\section{Stay of Proceeding}

The alleged infringer may request to stay the infringement proceeding until a decision concerning a parallel patent validity challenge becomes available. If the validity challenge is entirely successful, the patent will be declared ex tunc invalid and any pending infringement proceeding will be discontinued. If the patent is partly revoked, the subject matter in the infringement proceeding will be considered based on the amended patent. A parallel invalidity proceeding can arise due to an opposition filed before the European Patent Office for EP patents, or before the German Trade Mark and Patent Office for $D E$ patents. After the opposition phase, invalidity proceedings for both kinds of patents are initiated through a revocation action filed before the German Federal Patent Court.

The delay to a judgment due to a stayed proceeding can be considerable. The German Federal Patent Court decides on validity in sixteen to twenty-four months. Including appeal, litigants have to expect a maximal length of up to five years until a final judgment on validity is given (Cremers et al., 2016b). Likewise, oppositions may take between three to four years.

\section{Damages}

The plaintiff may demand compensation for economic loss due to the infringement. The question of the level of damages is usually answered in a separate, subsequent proceeding. Three methods of calculating damages are available: based on the plaintiff's lost profits, on the infringer's gained profits, or per license analogy. The plaintiff is free to choose the method, independent of his status or market activities. The calculation method based on the plaintiff's lost profits is rarely applied in proceedings on the amount of damages. This is mainly due to the plaintiff's requirement to disclose his accounts in the proceeding and the challenge to provide evidence for causality between

\footnotetext{
${ }^{27}$ In fact, it may constitute grounds for an appeal if a judge clearly overestimates his understanding of certain aspects of the case.
} 
the infringement and unrealized profits. Likewise, plaintiffs consider compensation based on the infringer's profit an unpopular choice, as the infringer is able to minimize her profits through the inclusion of overhead costs. Accordingly, the license analogy calculation is the most widely used (Reitzig et al., 2007; Kühnen, 2012). Here, the amount of damages is calculated based on what the infringer would have had to pay as reasonable fees if she had entered a license agreement. While calculation based on license analogy is considered a simple and convenient method, it usually constitutes only the lower limit of the plaintiff's economic loss due to infringement (Müller-Stoy and Schachl, 2011).

In comparison with pro-patentee damages rules applied in other countries, such as the U.S. or France (cf. Cotter, 2013), compensation claims remain a barely effective part of patent enforcement in Germany. Applying the concept of backward-looking and forward-looking remedies from Section 2, we consider Germany a jurisdiction where forward-looking remedies are more favorable than backward-looking remedies.

\section{Data and Construction of Variables}

\subsection{Data}

We draw upon a dataset of patent litigation proceedings filed between 2003 and 2008 in Germany and use several additional data sources to complement the data with respect to the characteristics of the litigants, the courts, and the patents in dispute.

\section{Infringement Proceeding}

We collected the data on infringement proceedings directly from court records stored at the three regional courts covering the most patent litigation cases in Germany: the Düsseldorf, Mannheim, and Munich regional courts. ${ }^{28}$ The dataset covers information on procedural aspects, the identity of the litigants and their legal representatives, and the patents at issue. In particular, we obtained information about when and how the proceedings ended; that is, by judgment, settlement, or withdrawal. If there was a judgment, we learned the outcome (win, partial win, loss) and whether an appeal was filed. We also acquired information on the litigation value set by the court and the claims made by the plaintiff, which helped us to identify noninfringement or adjacent proceedings (cf. Section 3.2).

\section{Litigants}

The data also include names and addresses of the litigants and their legal representatives. After matching the names of corporate litigants to firm level databases, including Bureau van Dijk's Orbis,

\footnotetext{
${ }^{28}$ For details on the collection process, see Cremers et al. (2016a).
} 
Compustat, and THOMSON One, we complemented the data with information on the litigants' fundamentals (number of employees, total assets, and turnover) and industry activities (NACE Rev. 2 industry codes). The data allow us to distinguish between natural and legal entities, such as firms, research institutions, universities, etc. We also identified non-practicing entities (NPEs) among corporate litigants in accordance with the methodology introduced in Helmers et al. (2014).

\section{Patents}

The litigated patents, as they are referenced in the case records by their application (and publication) numbers, were linked with the PATSTAT patent database. We retrieved bibliographic and procedural information on the patents, such as application and examination dates, IPC classifications, and patent as well as nonpatent references. In addition, we acquired information on validity challenges in the form of oppositions and revocation proceedings from the legal status information from PATSTAT, the German Patent and Trademark Office register, and the German Federal Patent Court.

\section{Courts}

We complemented our dataset with further information about the three regional courts, based on the regional courts' annual case assignment plans. The case assignment plan defines the subject matter each chamber will hear and how cases are allocated if more than one chamber can hear the case. The case assignment plan also designates each chamber's presiding judge and the pool of sitting judges. We obtained biographical data on the presiding judges, i.e., age, current and prior positions, and courts of employment. ${ }^{29}$

\subsection{Construction of Variables}

In the following, we briefly describe the variables constructed from our dataset. We distinguish between variables which capture characteristics of the patent, the court, and the dispute.

\section{Patent Characteristics}

As discussed in Section 3.2, infringement proceedings may be subject to delay due to a stay of proceedings or the request for an expert opinion. The request for an expert opinion largely depends on the technological intricacy ${ }^{30}$ of the litigated patent, while the grant of a stay of proceedings depends primarily on the patent's legal quality. The intricacy of a patent is primarily derived from two sources. The first is the depth and specificity of the patented technology. The second is the degree of originality and detachment of the patented technology from established technologies. Both

\footnotetext{
${ }^{29}$ This information is publicly available via the various editions of the handbook on Germany's judicial system (Handbuch der Justiz), which is published biennially by the German association of judges.

${ }^{30}$ The technological complexity of a patent commonly refers to the cumulative nature of the invention (Cohen et al., 2000). We therefore use the term intricacy to avoid confusion.
} 
characteristics make it hard for laypersons, such as judges, to comprehend the patent at issue and define its scope. A patent's quality is best measured by how well it fulfills the statutory requirements of patentable subject matter, novelty, nonobviousness and disclosure. Unfortunately, we are unable to analyze these criteria to determine the likelihood of invalidity and must therefore rely on the outcomes of prior invalidity proceedings. In line with Cremers et al. (2016b), we assume that patents that survived an opposition or revocation proceeding have solidified their validity. With a comprehensive set of patent characteristics, we aim to control for intricacy, quality as well as value of the litigated patent (cf. Table B-6 in the Appendix for an overview).

\section{Court Characteristics}

Expertise of judges German judges are mostly self-educated in technical matters (Ann, 2009). Moore (2001a) argues that judges gain technical expertise primarily from frequent exposure to the technology. We follow the general approach of Kesan and Ball (2011), who measure expertise by the prior caseload and seniority of a judge. ${ }^{31}$ We also take into account whether the judge can draw on prior infringement decisions based on the same patent.

\section{Dispute Characteristics}

Expected length of proceeding In his court selection problem, the plaintiff may consider the expected length of proceeding at each court. However, the length of proceeding ex ante expected by the plaintiff is a latent variable. On account of this, we predict the expected length for each proceeding at all three courts (cf. Section 6.1 for methodological details).

Litigation Value To quantify the scope of infringement, we draw on the litigation value as set by the court. In the few cases where the litigation value was adjusted during the proceeding, we choose the most recent one.

Distance to Court This variable can be seen as a proxy for the court-specific part of litigation costs. In case of multiple plaintiffs or defendants, we choose the one with the shortest distance to the court. ${ }^{32}$

Product Market Proximity We propose that determinants of court selection may depend on the litigants' product market proximity to each other. To operationalize market proximity, we use the

\footnotetext{
${ }^{31}$ Formally speaking, we define the expertise of a judge $g$ in a certain technology $x$ in year $y$ of his tenure as the judge's prior exposure to that technology area since the beginning of his presidency. We operationalize this exposure as the sum of all prior patent infringement disputes $I$ with a patent of technology $x$ that required the judge's involvement: Prior exposure ${ }_{g x y}=\log \left(\sum_{y=0}^{Y-1} \sum_{i=1}^{I}\right.$ Case $\left._{\text {gixy }}+1\right)$. We further include the tenure of the presiding judge in years as an additional variable.

${ }^{32}$ We calculate the variable by retrieving longitudinal and latitudinal data through the Google Maps API (Ozimek and Miles, 2011). For litigants from outside of Continental Europe, travel distance is not calculable. Here, we use an approximate distance based on the flight distance between the courts and each of the litigants' countries.
} 
overlap of the corporate litigants' market activities captured by industry codes available from firm level databases. Our constructed product market proximity variable is binary, with 1 reflecting an overlap of market activities with at least one industry code shared by plaintiff and defendant. ${ }^{33}$

\section{Control Variables}

Litigant Size and Residence To account for the litigant's stress due to the occupation of financial and human resources in the proceeding, we include a variable capturing the size of each litigant. The size categories follow the EU definition and rest upon the litigant's number of employees, turnover, and total assets. ${ }^{34}$ We take the residence of the litigants into account and distinguish between German, European and non-European litigants.

Legal Representatives While court selection is commonly understood as an essential part of pretrial strategy, legal representatives likely have different information on court-specific characteristics available to them. In particular, small law firms or self-employed attorneys probably lack the resources and knowledge to identify the optimal court. We include a dummy variable indicating whether the plaintiff or defendant's legal representative is considered a top law firm for patent litigation in Germany. ${ }^{35}$

Multi-jurisdictional Litigation The rationale for court selection in patent disputes where the litigants encounter each other before court in multiple countries is very likely to differ. We therefore identify multi-jurisdictional litigation by matching patent numbers and litigants from our data with available litigation data for the UK (England and Wales), France, and the Netherlands (cf. Cremers et al., 2016a).

\footnotetext{
${ }^{33} \mathrm{Natural}$ persons as well as nonpracticing entities, including research institutions, universities and patent assertion entities, are by definition not active in any product market. Therefore, their product market proximity to any alleged infringer is always 0 .

${ }^{34}$ In case of multiple plaintiffs or defendants, we give the largest party priority. As an alternative measure, we gathered the fundamentals for all parties on one side. The results do not change significantly.

${ }^{35}$ We use the annual ranking published by the professional journal JUVE Rechtsmarkt in 2009. As an alternative measure, we classified top legal representatives as those law firms that represent more cases than the average law firm in our data. The two measures are highly correlated.
} 


\section{Descriptive Analysis}

\section{Sample Description}

Our data from the Düsseldorf, Mannheim and Munich regional courts during the period 2003 to 2008 contain 2,599 patent infringement proceedings. ${ }^{36}$ Most of these cases were filed before the Düsseldorf regional court (1,719 cases). The Mannheim regional court is next with 692 and followed by the Munich regional court with 188 cases. We merged these cases with additional information on patent characteristics and litigants.

Considerations for court selection in preliminary injunction requests likely differ from those in patent infringement proceedings. Here, the infringing act can be halted through the granting of a preliminary injunction, to the effect that the plaintiff is relieved of potentially foregone earnings. We therefore focus only on cases without a prior request for preliminary injunction.

\section{Descriptive Statistics}

In the following we present aggregated court data. First, Figure 1 illustrates the distribution of proceedings filed between 2003 and 2008 across the three regional courts. ${ }^{37}$ Düsseldorf comfortably leads the field with Mannheim and Munich as the second and third busiest courts, respectively. Neither the distribution nor the settlement rate shows heavy fluctuations for our time frame. Notably, the caseload in Mannheim increases considerably after the establishment of the second chamber in 2005. A causal relationship between the enlarged capacities at the Mannheim court and the rise in cases is in line with statements made by interviewed practitioners.

Comparing the outcomes of proceedings across courts, Table 1 implies that the Düsseldorf regional court rules that patents have been (partly) infringed more often than Mannheim and Munich. When excluding settlements, Mannheim shows the highest win-rate for patent holders.

Looking at the densities of the length of proceeding by court in Figure 2, we observe that the three courts significantly differ in the time needed until judgment. The length of ordinary proceedings can be easily identified for the Düsseldorf and Mannheim regional courts. The high density around 400 days indicates the average length of an ordinary main proceeding with judgment in Düsseldorf. Ordinary main proceedings in Mannheim end on average after 280 days. The relatively fat tail to the right for proceedings in Mannheim, however, indicates a higher likelihood of delaying events

\footnotetext{
${ }^{36}$ For the purpose of our study, we want to achieve a homogeneous sample of patent infringement main proceedings. We therefore removed cases in which the subject matter suggests that the litigants were previously in a contractual relationship. This includes cases on employee invention disputes, licensing, assignment, and patent transfer disputes. We also dropped infringement actions based on utility models. As our focus is on patent infringement main proceedings, we removed single preliminary injunctions and adjacent proceedings, such as cost or damages proceedings.

${ }^{37}$ We assume the caseload in 2008 is actually slightly larger than our data reflect, due to some still pending cases at the time of collection in 2011.
} 
Figure 1: Number of proceedings with judgment and settlement by regional court and year

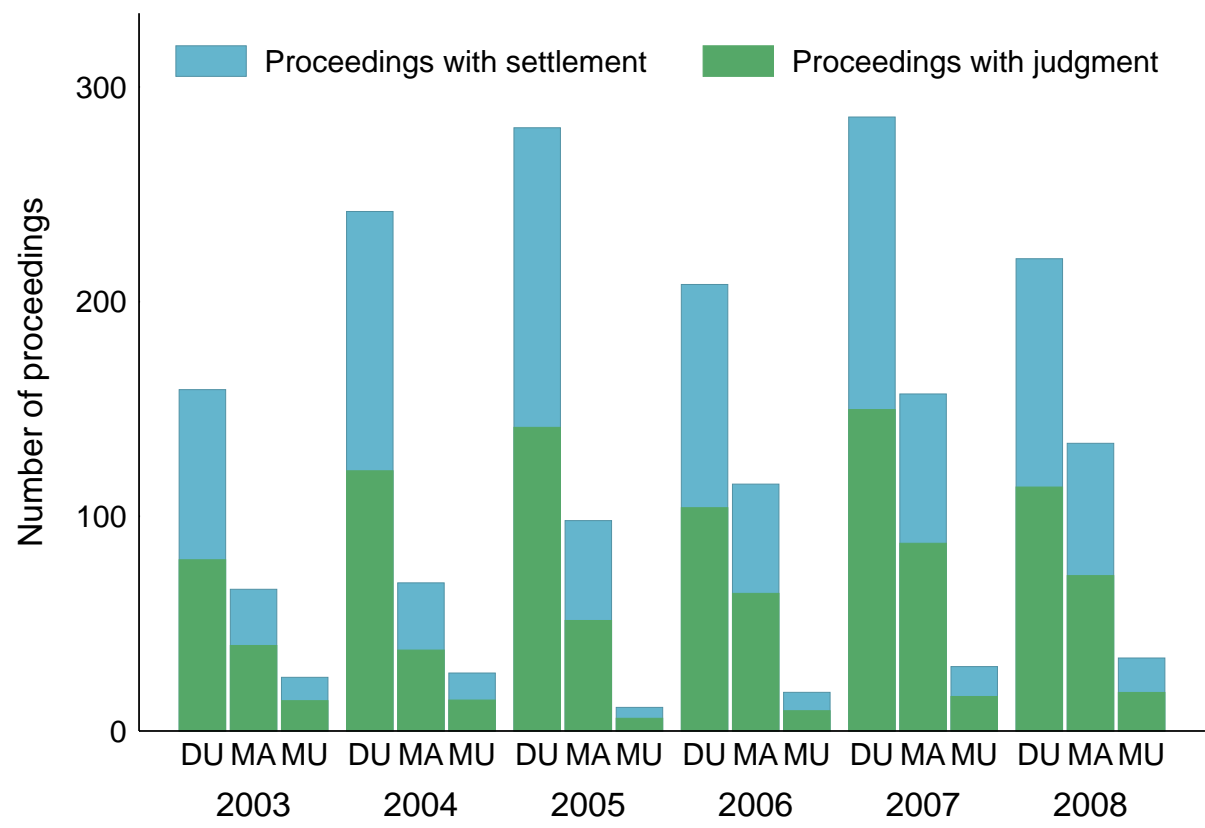

Notes: The sample consists of all patent infringement proceedings. The unit of observation is the infringement proceeding. Judgments include judgments by contention and by default decree. Settlements include withdrawals as well as (out-of-court) settlements. Requests for preliminary injunctions excluded.

compared to Düsseldorf. ${ }^{38}$

In Mannheim and Munich, settlements take place largely within the first 100 days. Most settlements in Düsseldorf occur at a later time right before or after the main hearing. We also observe that at all three courts cases frequently settle at a point after ordinary proceedings usually end. That

Table 1: Outcomes of infringement main proceedings by regional court

\begin{tabular}{|c|c|c|c|c|c|c|c|c|}
\hline \multirow[b]{3}{*}{ Outcome } & \multicolumn{6}{|c|}{ Regional court } & & \\
\hline & \multicolumn{2}{|c|}{ LG DU } & \multicolumn{2}{|c|}{ LG MA } & \multicolumn{2}{|c|}{ LG MU } & \multicolumn{2}{|c|}{ Total } \\
\hline & $\mathrm{N}$ & $\%$ & $\mathrm{~N}$ & $\%$ & $\mathrm{~N}$ & $\%$ & $\mathrm{~N}$ & $\%$ \\
\hline infringed & 286 & $20.7 \%$ & 131 & $20.6 \%$ & 27 & $19.0 \%$ & 444 & $20.6 \%$ \\
\hline partly infringed & 145 & $10.5 \%$ & 27 & $4.2 \%$ & 11 & $7.7 \%$ & 183 & $8.5 \%$ \\
\hline not infringed & 212 & $15.4 \%$ & 58 & $9.1 \%$ & 26 & $18.3 \%$ & 296 & $13.7 \%$ \\
\hline settlement & 736 & $53.4 \%$ & 421 & $66.1 \%$ & 78 & $54.9 \%$ & 1,235 & $57.2 \%$ \\
\hline Total & 1,379 & $100.0 \%$ & 637 & $100.0 \%$ & 142 & $100.0 \%$ & 2,158 & $100.0 \%$ \\
\hline
\end{tabular}

Notes: The sample consists of all patent infringement proceedings. The unit of observation is the infringement proceeding. Settlements include withdrawals as well as (out-of-court) settlements. Requests for preliminary injunctions excluded.

\footnotetext{
${ }^{38}$ Interpreting the density of the lengths of proceeding for Munich is less meaningful due to the relatively small number of cases. A considerable share of proceedings apparently ends as early as in Mannheim, however, several humps at later points in time imply delaying events.
} 
Figure 2: Length of infringement main proceedings with judgment and settlement by court (densities)
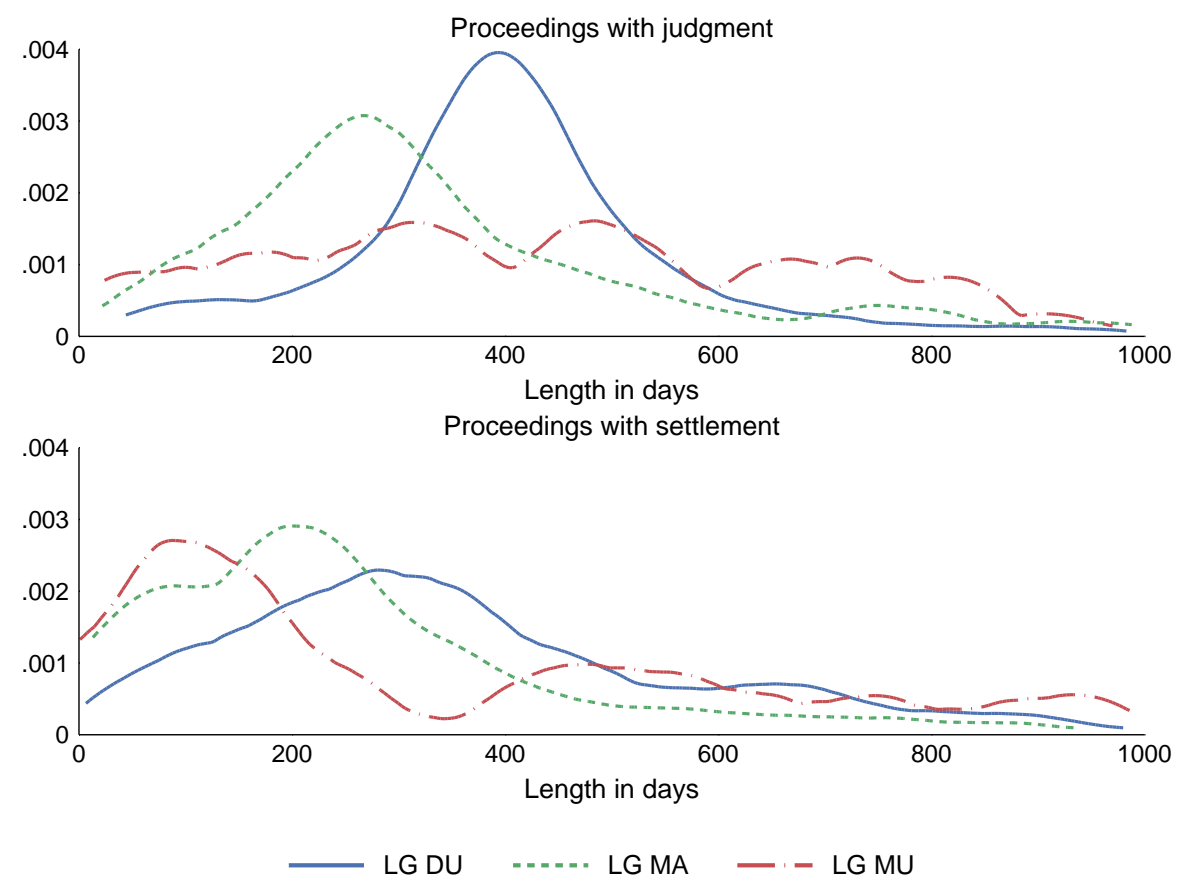

Notes: The sample consists of all patent infringement proceedings based on patents in force. The unit of observation is the infringement proceeding. Judgments include judgments by contention and by default decree. Settlements include withdrawals as well as (out-of-court) settlements. Truncated at 1,000 days.

is, litigants may decide to settle a case when the proceeding becomes subject to a delaying event, rather than wait for judgment.

Based on the assumption that plaintiffs prefer a fast resolution of their dispute and pro-patentee outcomes, we are not able to explain why the regional court in Düsseldorf attracts considerably more plaintiffs than the regional courts in Mannheim and Munich using aggregate court level data alone.

We now turn to characteristics of the court-specific populations of patent disputes with a brief description of the summary statistics in Table B-1 in the Appendix. Several significant differences are observable across the regional courts. Most notably, the average litigation value is more than twice as high in Düsseldorf than at the other two courts. ${ }^{39}$ We further observe a parallel invalidity proceeding in about $50 \%$ of all proceedings at the Düsseldorf regional court. The rate is even higher in Mannheim, at 60\%, but only 40\% in Munich. Conditional on such a parallel invalidity proceeding, the rate of a granted stay is lower for Düsseldorf and Mannheim, at 18\% compared to 30\% in Munich. Likewise, expert opinions are requested about twice as often in Munich (20\%) as in Düsseldorf (8\%) or Mannheim (12\%).

While the average size of patent holders is significantly smaller at the Munich regional court compared to the other two courts, the share of large alleged infringers is greatest at the Düsseldorf

\footnotetext{
${ }^{39}$ The differences cannot be explained by different technology distributions (see Table B-2 in the Appendix).
} 
regional court. Notably, the Mannheim regional court attracts by far the most nonpracticing entities. ${ }^{40}$ We break down the nationalities of the litigants at each court and find strong concentrations of patent holders from certain countries at the courts (cf. Table B-3 in the Appendix). For instance, Japanese patent holders file their actions almost exclusively in Düsseldorf.

The distribution of technology areas is quite remarkable. The regional court in Mannheim predominantly hears disputes on patents in the field of electrical engineering, while Düsseldorf hears the most cases on chemistry patents. We plotted the litigants with German residency on a country map to visualize the spatial distribution by court and technology main area (cf. Figures A-4 and A-5 in the Appendix). Although the concentration of patent holders and alleged infringers in west and southwest Germany mirrors the location of important industrial regions, neither the existence nor the proximity of industrial clusters can fully explain the number of cases and the disproportionate representation of technology areas at the three regional courts. ${ }^{41}$

\section{Empirical Model and Results}

\subsection{Empirical Model}

\section{Modeling Court Selection}

The primary goal of our econometric model of court selection is to recover estimates of the plaintiffs' preferences. To do so, we draw on an additive random-utility model. For the plaintiff of dispute $i$ and chosen court $j$ among $J$ courts with $J=\{D U, M A, M U\}$, the utility $U_{i j}$ is the sum of the deterministic component $V_{i j}$ and the unobserved random term $\epsilon_{i j}$. We observe the outcome $y_{i}=j$ if $U_{i j}>U_{i k} \quad \forall \quad k \neq j$. Accordingly, we specify our alternative-specific conditional logit model with the error terms as iid extreme value distributed:

$$
U_{i j}=\boldsymbol{\beta} X_{i j}^{\prime}+\boldsymbol{\gamma}_{j} Z_{i}^{\prime}+\epsilon_{i j}
$$

so that

$$
p_{i j}=\operatorname{Pr}\left(y_{i}=j\right)=\frac{\exp \left(\boldsymbol{\beta} \boldsymbol{X}_{i j}^{\prime}+\boldsymbol{\gamma}_{j} \boldsymbol{Z}_{i}^{\prime}\right)}{\sum_{k=1}^{n} \exp \left(\boldsymbol{\beta} \boldsymbol{X}_{i j}^{\prime}+\boldsymbol{\gamma}_{j} \boldsymbol{Z}_{i}^{\prime}\right)} \quad \text { with } \quad j=D U, M A, M U \text {, }
$$

where the vector $\boldsymbol{X}_{i j}^{\prime}$ represents alternative-specific regressors and vector $\boldsymbol{Z}_{i}^{\prime}$ covers case-specific regressors. The alternative-specific regressors $X_{i j}^{\prime}$ include the expected length of proceeding, the distance to court of both the plaintiff and the defendant. The case-specific regressors $Z_{i}^{\prime}$ include year, technology and litigant (size, residence, market activity and legal representation) controls as well as a dummy whether the plaintiff had any prior case at the court.

\footnotetext{
${ }^{40}$ Nonpracticing entities are primarily active in the field of electrical engineering technologies.

${ }^{41}$ For instance, the Mannheim regional court sees very few cases on chemistry patents, even though the surrounding Rhein-Neckar-Gebiet is host to a large cluster of chemical firms.
} 
The plaintiff of dispute $i$ goes to court $y_{i}$ that corresponds to the highest value function, i.e.,

$$
y_{i}=\arg \max _{j \in\{D U, M A, M U\}} U_{i j} .
$$

Using cross-sectional data with each observation representing a dispute, our main empirical specification is as follows:

$$
\begin{aligned}
& U_{i j}=\beta_{1} \text { Expected length }_{i j}+\beta_{2} \text { Plaintiff distance to court }_{i j}+\beta_{3} \text { Defendant distance to } \text { court }_{i j}+ \\
& +\gamma_{1 j} \text { Prior case at court }_{i}+\gamma_{2 j} \text { Litigation value }{ }_{i}+\gamma_{3 j} \text { Plaintiff characteristics }{ }_{i}+ \\
& +\gamma_{4 j} \text { Defendant characteristics }_{i}+\gamma_{5 j} \text { Technology }_{i}+\gamma_{6 j} \text { Year }_{i}+\epsilon_{i j} \text {. }
\end{aligned}
$$

Following from the theoretical model set out in Section 2, we anticipate that $\beta_{1}<0$ and $\beta_{2}<0$; i.e., an increase in the plaintiff's expected length of trial and distance to one court increases the probability of selecting an alternative court. If we find that $\gamma_{2 j} \neq \gamma_{2 k} \exists k \neq j$, we can infer that plaintiffs assume court-specific probabilities to win their case. For instance, if $\gamma_{2 j}<\gamma_{2 k}$, the plaintiffs perceive court $j$ as less patent-friendly than court $k$. Thus, the higher the scope of infringement (proxied by the variable Litigation value), the more likely a plaintiff is to select the alternative court $k$, where the expected liability of infringement is higher. This follows from the reasoning that the benefit of going to a more pro-patentee court increases with the scope of infringement.

\section{Predicting the Expected Length of Proceeding}

One of our main variables of interest, the expected length of proceeding, remains unobserved in our data for multiple reasons. First, we only observe the actual length of proceeding at the selected court, not at alternative courts. Second, a considerable share of proceedings end prematurely in settlement. Third, the actual length of the proceeding is chamber-specific that may diverge from the court-specific expected length. ${ }^{42}$ For all these reasons, we are left with an unclear picture of the length of proceeding a plaintiff initially associates with a particular court.

To gain insight what length of proceeding each plaintiff may expect at each court, we make use of the fact that before German regional courts infringement proceedings are characterized by a very structured process that offers de facto only two discrete events as cause for considerable delay (cf. Section 3.2). ${ }^{43}$ Formally, we depict the expected length of proceeding until judgment at each court $j$ for each case $i$ as follows:

$$
\begin{aligned}
& \left.\widehat{l}_{i j}=\bar{l}_{j}^{\text {ord }}+\operatorname{Pr}_{i j}(\widehat{\text { inv. proc. }}=1) \cdot \operatorname{Pr}_{i j}(\text { stay } \overline{=1 \mid \text { inv. }} \text { proc. }=1) \cdot l^{\text {stay }}+\operatorname{Pr}_{i j} \widehat{(\text { expert }}=1\right) \cdot \bar{l}^{\text {expert }}- \\
& -\operatorname{Pr}_{i j}(\widehat{\text { inv. proc. }}=1) \cdot \operatorname{Pr}_{i j}(\text { stay } \widehat{=1 \mid \text { inv. }} \text { proc. }=1) \cdot \operatorname{Pr}_{i j}(\widehat{\text { expert }}=1) \cdot \min \left(l^{\text {stay }}, \bar{l}{ }^{\text {expert }}\right) \text {. }
\end{aligned}
$$

\footnotetext{
${ }^{42}$ This is the case if the court has two chambers and the respective judges in charge differ, e.g., in terms of expertise. The plaintiff cannot foresee which chamber his case will be assigned to.

${ }^{43}$ This is in stark contrast to the U.S., where litigants enjoy considerable leeway to influence the length of proceeding.
} 
This equation makes the following simplifying assumptions: the expected length of any ordinary proceeding is exogenously given and set to the median length of all proceedings with judgment at a specific court in a given year (year indices omitted). Further, the probabilities of the two delaying events, namely stay and expert opinion, are predicted based on the results of parametric models estimating the case-specific probabilities of either event (cf. Table B-4 for an overview).

One concern raised by the above approach is that delaying events remain partly unobserved due to settlements. Omitting cases with settlement in the first-stage regression may lead to a distorted out-of-sample prediction of the probabilities of delaying events. Constructed from original case documents, our data entail information on the court's decision to stay or to request an expert even if the proceeding ended in a settlement shortly after. We can therefore extend our first-stage sample to all proceedings that did not end in a settlement prior to the main oral hearing, which usually reveals how the court decides on a stay and the need for an expert opinion. This increases the sample for our first-stage regression considerably and minimizes potential selection problems.

Besides the probabilities of the two delaying events, we further need to define how long a judgment will be deferred if the court decides to stay the proceeding ( $\left.l^{\text {stay }}\right)$ or request an expert opinion $\left(\bar{l}^{\text {expert }}\right)$. The general term $l^{\text {stay }}$ can be either dispute-specific, $l_{i j}^{\text {stay }}$, if an invalidity proceeding is already pending at the time of the plaintiff's court selection, or a general estimation, $\bar{l}_{j}^{\text {stay }}$, if no invalidity action is pending at the time of the plaintiff's court selection. ${ }^{44}$ We fix the delay caused by an expert opinion ( $\left.\bar{l}^{\text {expert }}\right)$ at 24 months across all three courts, which is in line with estimates by Kühnen (2012) and interviewed practitioners.

We estimate the probability for each event independently. Characteristics associated with the patent in dispute $\left(P A T_{i}\right)$, the litigants $\left(L I T_{i}\right)$, the proceeding $\left(P R O C_{i}\right)$, and the judges $\left(J U D_{j}\right)$, comprise the regressors in our estimations. ${ }^{45}$ We predict the probability of the request for an expert opinion with the following probit model:

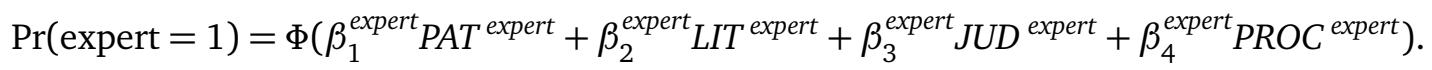

As the stay of a proceeding is conditional on a parallel invalidity proceeding, we need to distinguish between two cases: whether an invalidity proceeding is already pending at the time of the plaintiff's court selection or not. In the latter case the probability of a stay is predicted by a probit model with sample selection. We specify the selection equation as

$$
\operatorname{Pr}(\text { inv. proc. }=1)=\Phi\left(\beta_{1}^{i n v} P A T^{i n v}+\beta_{2}^{i n v} L I T^{i n v}+\beta_{3}^{i n v} J U D^{i n v}+\beta_{4}^{i n v} P R O C^{i n v}\right),
$$

\footnotetext{
${ }^{44}$ The length of the stay $\bar{l}_{j}^{\text {stay }}$ is determined exogenously as the difference between the median lengths of all first instance revocation/opposition proceedings filed in that year plus the observed time difference (median time difference) between the filing of the invalidity proceeding and the filing of the infringement proceeding $\Delta_{i}(\bar{\Delta})$ plus the court-specific expected length of the ordinary proceeding $\bar{l}_{j}^{\text {ord }}$. For a year-by-year overview of $\bar{l}_{j}^{\text {stay }}$, see Table B-5 in the Appendix.

${ }^{45}$ Table B-4 in the Appendix gives an overview of which characteristics are used in which model to regress the respective delaying event.
} 
and the resultant binary outcome equation as

$$
\operatorname{Pr}(\text { stay }=1 \mid \text { inv. proc. }=1)=\Phi\left(\beta_{1}^{\text {stay }} P A T^{\text {stay }}+\beta_{2}^{\text {stay }} L I T^{\text {stay }}+\beta_{3}^{\text {stay }} J U D^{\text {stay }}+\beta_{4}^{\text {stay }} P R O C^{\text {stay }}\right) .
$$

We use the distance of the alleged infringer to the invalidity court as exclusion restrictions. ${ }^{46}$ This distance likely plays a role in the propensity to file an invalidity proceeding, but should not affect the court's decision to actually grant a stay.

When regressing the decision to request an expert opinion, we can reject equal propensities among the courts (cf. Table 2). With the first chamber at the Düsseldorf regional court as baseline, we observe a positive effect of the chambers at the remaining two courts on the likelihood of an expert opinion. Our constructed measures of the judges' expertise appear significant. In regression (E4) we include technology chamber interactions - the court effects remain significant. We can conclude that the regional courts in Mannheim and Munich are in general more likely to request expert opinions than the Düsseldorf regional court, with Munich even more likely to do so than Mannheim.

Table 3 shows the results of regressing the decision to grant a stay of the infringement proceeding conditional on a parallel invalidity proceeding. Notably, the litigation value has no effect on the court's tendency to grant a stay, but has a highly significant effect on the alleged infringer to file a validity challenge. The results of the selection equation show that the courts hearing the infringement proceeding has small, throughout insignificant, effect on the likelihood of a validity challenge. In contrast, the results of the outcome equation show highly significant court effects. We find that the Mannheim and Munich regional courts are considerably more likely to stay a proceeding compared to the two chambers in Düsseldorf.

Having identified the determinants of the likelihood of delaying events, we are now able to predict the expected length of proceeding for each case at each court. We adjust chamber-specific variables to court-specific variables where necessary, and impute ex ante unknown variables (lag of invalidity proceeding and the decision on noninfringement) with average values. We then perform out-of-sample predictions of the likelihood for delaying events for all cases at each court (cf. Table 4). With these values we calculate the expected lengths of proceeding. The densities of the predicted court-specific lengths can be found in Figure 3 for all proceedings and in Figure A- 6 in the Appendix broken down by technology area.

In contrast to Figure 2, the Düsseldorf regional court now appears to be faster than the Mannheim and Munich regional courts. Although the Mannheim regional court may still be faster than the Düsseldorf regional court, the majority of cases seem to take considerably longer. This is because the probability of delaying events weighs heavier on the expected length of proceedings in Mannheim and Munich than in Düsseldorf for majority of cases within the unconditional population of cases.

\footnotetext{
${ }^{46}$ That is, we include the corresponding variable in the selection equation, but exclude it from the binary outcome equation.
} 
Table 2: Probit model results: incidence of expert opinion

\begin{tabular}{|c|c|c|c|c|}
\hline Dependent variable: expert opinion & (E1) & $(\mathrm{E} 2)$ & (E3) & (E4) \\
\hline \multicolumn{5}{|l|}{ Court effects } \\
\hline Chamber 2 (LG DU) (d) & $\begin{array}{c}0.026 \\
(0.025)\end{array}$ & $\begin{array}{c}0.029 \\
(0.026)\end{array}$ & $\begin{array}{c}0.039 \\
(0.025)\end{array}$ & $\begin{array}{c}-0.032 \\
(0.054)\end{array}$ \\
\hline Chamber 1 (LG MA) (d) & $\begin{array}{c}0.162^{* * *} \\
(0.041)\end{array}$ & $\begin{array}{c}0.148^{* * *} \\
(0.038)\end{array}$ & $\begin{array}{c}0.279^{* * *} \\
(0.064)\end{array}$ & $\begin{array}{c}0.372^{* * *} \\
(0.125)\end{array}$ \\
\hline Chamber 2 (LG MA) (d) & $\begin{array}{c}0.268^{* * *} \\
(0.058)\end{array}$ & $\begin{array}{c}0.211^{* * *} \\
(0.053)\end{array}$ & $\begin{array}{c}0.362^{* * *} \\
(0.076)\end{array}$ & $\begin{array}{c}0.372^{* *} \\
(0.164)\end{array}$ \\
\hline Chamber 1 (LG MU) (d) & $\begin{array}{c}0.233^{* * *} \\
(0.064)\end{array}$ & $\begin{array}{c}0.233^{* * *} \\
(0.064)\end{array}$ & $\begin{array}{c}0.588^{* * *} \\
(0.118)\end{array}$ & $\begin{array}{r}0.432^{*} \\
(0.222)\end{array}$ \\
\hline Chamber 2 (LG MU) (d) & $\begin{array}{c}0.197^{* * *} \\
(0.066)\end{array}$ & $\begin{array}{l}0.209^{* * *} \\
(0.067)\end{array}$ & $\begin{array}{l}0.518^{* * *} \\
(0.114)\end{array}$ & $\begin{array}{c}0.551^{* * *} \\
(0.154)\end{array}$ \\
\hline \multicolumn{5}{|l|}{ Procedural characteristics } \\
\hline Litigation value (in th $€, \log$ ) & $\begin{array}{c}0.007 \\
(0.012)\end{array}$ & $\begin{array}{c}0.009 \\
(0.009)\end{array}$ & $\begin{array}{c}0.012 \\
(0.009)\end{array}$ & $\begin{array}{c}0.009 \\
(0.009)\end{array}$ \\
\hline Multi-jurisdictional litigation (d) & & & $\begin{array}{c}0.012 \\
(0.055)\end{array}$ & $\begin{array}{c}0.022 \\
(0.057)\end{array}$ \\
\hline \multicolumn{5}{|l|}{ Judicial expertise } \\
\hline Tenure as judge (in years) & & & $\begin{array}{c}-0.007^{* *} \\
(0.003)\end{array}$ & $\begin{array}{c}-0.009^{* * *} \\
(0.003)\end{array}$ \\
\hline Prior exposure to technology area (log) & & & $\begin{array}{c}0.051^{* * *} \\
(0.016)\end{array}$ & $\begin{array}{c}0.067^{* * *} \\
(0.019)\end{array}$ \\
\hline Prior infringement decision on patent (d) & & & $\begin{array}{c}-0.037 \\
(0.029)\end{array}$ & $\begin{array}{c}-0.040 \\
(0.027)\end{array}$ \\
\hline Chamber $\times$ Technology effects & No & No & No & Yes \\
\hline Patent characteristics & No & Yes & Yes & Yes \\
\hline Litigant characteristics & No & No & No & Yes \\
\hline Technology effects & No & No & No & Yes \\
\hline Year effects & No & No & Yes & Yes \\
\hline Pseudo $R^{2}$ & 0.044 & 0.061 & 0.081 & 0.118 \\
\hline Observations & 1,596 & 1,596 & 1,596 & 1,596 \\
\hline
\end{tabular}

Marginal effects; Clustered standard errors in parentheses

(d) for discrete change of dummy variable from 0 to 1

${ }^{*} p<0.10,{ }^{* *} p<0.05,{ }^{* * *} p<0.01$

Notes: The sample consists of all patent infringement proceedings that did not end in settlement prior to the call for an expert opinion. The unit of observation is at the case level. Base line: Chamber 1 (LG DU). Standard errors clustered by patent. 
Table 3: Probit model with sample selection results: incidence of stay of proceeding

\begin{tabular}{|c|c|c|c|c|}
\hline & \multicolumn{2}{|c|}{$(\mathrm{S} 1)$} & \multicolumn{2}{|c|}{ (S2) } \\
\hline & INF stayed & INV filed & INF stayed & INV filed \\
\hline \multicolumn{5}{|l|}{ Court effects } \\
\hline Chamber 2 (LG DU) & $\begin{array}{c}0.033 \\
(0.120)\end{array}$ & $\begin{array}{c}0.067 \\
(0.089)\end{array}$ & $\begin{array}{c}0.037 \\
(0.119)\end{array}$ & $\begin{array}{c}0.048 \\
(0.090)\end{array}$ \\
\hline Chamber 1 (LG MA) & $\begin{array}{c}0.749^{* * *} \\
(0.160)\end{array}$ & $\begin{array}{c}0.166 \\
(0.128)\end{array}$ & $\begin{array}{c}0.816^{* * *} \\
(0.168)\end{array}$ & $\begin{array}{c}0.197 \\
(0.133)\end{array}$ \\
\hline Chamber 2 (LG MA) & $\begin{array}{l}0.711^{* * *} \\
(0.212)\end{array}$ & $\begin{array}{c}0.268 \\
(0.177)\end{array}$ & $\begin{array}{c}0.750^{* * *} \\
(0.207)\end{array}$ & $\begin{array}{c}0.276 \\
(0.186)\end{array}$ \\
\hline Chamber 1 (LG MU) & $\begin{array}{c}0.260 \\
(0.255)\end{array}$ & $\begin{array}{c}0.078 \\
(0.199)\end{array}$ & $\begin{array}{c}0.307 \\
(0.261)\end{array}$ & $\begin{array}{c}0.106 \\
(0.204)\end{array}$ \\
\hline Chamber 2 (LG MU) & $\begin{array}{c}0.775^{* *} \\
(0.329)\end{array}$ & $\begin{array}{c}-0.319 \\
(0.200)\end{array}$ & $\begin{array}{c}0.833^{* *} \\
(0.349)\end{array}$ & $\begin{array}{r}-0.253 \\
(0.195)\end{array}$ \\
\hline \multicolumn{5}{|l|}{ Procedural characteristics } \\
\hline Ruled: not infringed & $\begin{array}{c}-1.018^{* * *} \\
(0.163)\end{array}$ & $\begin{array}{c}0.070 \\
(0.104)\end{array}$ & $\begin{array}{c}-1.047^{* * *} \\
(0.186)\end{array}$ & $\begin{array}{c}0.017 \\
(0.102)\end{array}$ \\
\hline Lag of invalidity proceeding (in days) & $\begin{array}{c}0.000 \\
(0.000)\end{array}$ & & $\begin{array}{c}0.000 \\
(0.000)\end{array}$ & \\
\hline Litigation value (in th $€, \log$ ) & $\begin{array}{c}0.122^{* *} \\
(0.062)\end{array}$ & $\begin{array}{l}0.271^{* * *} \\
(0.041)\end{array}$ & $\begin{array}{c}0.100 \\
(0.061)\end{array}$ & $\begin{array}{c}0.221^{* * *} \\
(0.043)\end{array}$ \\
\hline Multi-jurisdictional litigation & $\begin{array}{l}0.662^{* * *} \\
(0.224)\end{array}$ & $\begin{array}{l}0.996^{* * *} \\
(0.304)\end{array}$ & $\begin{array}{l}0.656^{* * *} \\
(0.226)\end{array}$ & $\begin{array}{l}1.052^{* * *} \\
(0.296)\end{array}$ \\
\hline \multicolumn{5}{|l|}{ Exclusion restriction } \\
\hline $\begin{array}{l}\text { Alleged infringer distance to invalidity court } \\
\text { (in th } \mathrm{km} \text { ) }\end{array}$ & & $\begin{array}{l}-0.148^{* * *} \\
(0.022)\end{array}$ & & $\begin{array}{l}-0.164^{* * *} \\
(0.060)\end{array}$ \\
\hline Patent characteristics & Yes & Yes & Yes & Yes \\
\hline Invalidity history & Yes & Yes & Yes & Yes \\
\hline Litigant characteristics & No & No & Yes & Yes \\
\hline Technology effects & Yes & Yes & Yes & Yes \\
\hline Year effects & Yes & Yes & Yes & Yes \\
\hline Observations & \multicolumn{2}{|c|}{1,669} & \multicolumn{2}{|c|}{1,669} \\
\hline
\end{tabular}

Clustered standard errors in parentheses

${ }^{*} p<0.10,{ }^{* *} p<0.05,{ }^{* * *} p<0.01$

Notes: The sample consists of all patent infringement proceedings based on patents in force that did not end in settlement prior to the call for an expert opinion. The unit of observation is at the case level. Base line regional court: Chamber 1 (LG DU). Standard errors clustered by patent. 
Table 4: Predicted likelihoods of delaying events by court and technology main area

\begin{tabular}{|c|c|c|c|c|c|c|}
\hline & \multicolumn{2}{|c|}{ Expert opinion } & \multicolumn{2}{|c|}{ Validity challenge } & \multicolumn{2}{|c|}{ Stay } \\
\hline & Mean & Std. dev. & Mean & Std. dev. & Mean & Std. dev. \\
\hline \multicolumn{7}{|c|}{ Electrical engineering } \\
\hline LG DU & 0.20 & 0.10 & 0.53 & 0.27 & 0.22 & 0.13 \\
\hline LG MA & 0.25 & 0.13 & 0.59 & 0.26 & 0.46 & 0.17 \\
\hline LG MU & 0.40 & 0.17 & 0.50 & 0.27 & 0.41 & 0.17 \\
\hline \multicolumn{7}{|c|}{ Instruments } \\
\hline LG DU & 0.09 & 0.06 & 0.70 & 0.27 & 0.21 & 0.12 \\
\hline LG MA & 0.36 & 0.16 & 0.74 & 0.24 & 0.46 & 0.15 \\
\hline LG MU & 0.22 & 0.11 & 0.67 & 0.28 & 0.40 & 0.15 \\
\hline \multicolumn{7}{|c|}{ Chemistry } \\
\hline LG DU & 0.10 & 0.07 & 0.74 & 0.29 & 0.21 & 0.11 \\
\hline LG MA & 0.22 & 0.12 & 0.77 & 0.27 & 0.46 & 0.15 \\
\hline LG MU & 0.39 & 0.15 & 0.72 & 0.30 & 0.40 & 0.14 \\
\hline \multicolumn{7}{|c|}{ Mechanical engineering } \\
\hline LG DU & 0.13 & 0.07 & 0.58 & 0.29 & 0.20 & 0.10 \\
\hline LG MA & 0.24 & 0.09 & 0.64 & 0.27 & 0.45 & 0.14 \\
\hline LG MU & 0.30 & 0.10 & 0.56 & 0.30 & 0.39 & 0.13 \\
\hline \multicolumn{7}{|l|}{ Other } \\
\hline LG DU & 0.10 & 0.06 & 0.52 & 0.30 & 0.16 & 0.10 \\
\hline LG MA & 0.28 & 0.10 & 0.57 & 0.29 & 0.40 & 0.15 \\
\hline LG MU & 0.16 & 0.08 & 0.50 & 0.31 & 0.34 & 0.14 \\
\hline All & 0.23 & 0.10 & 0.59 & 0.29 & 0.34 & 0.14 \\
\hline
\end{tabular}

Notes: The sample consists of all patent infringement proceedings based on patents in force. The unit of observation is at the case level. The results reflect out-of-sample predictions; that is, predictions are on all proceedings for each court. Predicted likelihoods of suspension conditional on a parallel validity challenge. 
Figure 3: Ex ante predicted lengths of infringement proceedings until judgment by court (densities)

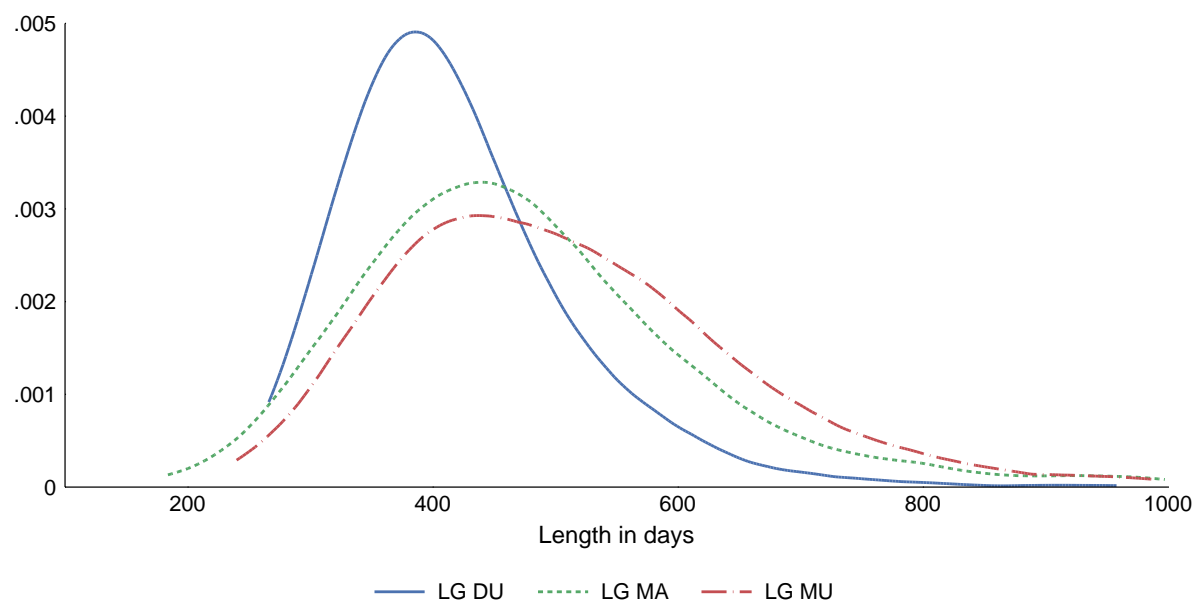

Notes: The unit of observation is the infringement proceeding. Truncated at 1,000 days.

\subsection{Results}

We now turn to the results of the alternative-specific conditional logit models on court selection. In Table 5 columns (C1) to (C3), we regress our main variables of interest, expected length of proceedings and distance to courts, on court selection with an increasing number of covariates. As we can see in column (C3), the expected length has a negative, yet insignificant, effect on court selection in the full specification. In column (C4), we add product market proximity as a further variable and interact it with the expected length of proceeding. We find that the interaction term Expected length $\times$ Market proximity shows a significant negative effect. These findings are in line with Prediction 4.

Litigants' distances to court show a highly significant and robust negative effect on court selection across all specifications, with the plaintiff's own distance to court having a considerably larger effect than the alleged infringer's distance to court. This confirms Predictions 1, 2 and 3.

Table 6 shows the results of several regressions with further interaction effects. In column (C5), we further interact product market proximity with litigants' distance to court. Neither the effect with the plaintiff distance nor the effect with the defendant distance is significant and large in size. This is in line with Prediction 5. Moreover, in column (C6), we interact the size of the plaintiff with the litigants' distance to court. The positive coefficient of the interaction term plaintiff distance to court and plaintiff large partly compensates the negative effect of distance, and implies that the distance to the court has a smaller effect on court choice if the plaintiff is a large firm.

In column (C7) and column (C8) we pay special attention to the determinants of court selection when the scope of infringement is large. We therefore introduce a dummy for cases where the litigation value is higher than 500 thousand $€$. Considering the interaction term consisting of the expected time, market proximity and litigation value, we observe that the time until judgment at a 
particular court matters the most when the plaintiff is in product market proximity with the alleged infringer and the litigation value is high. We consider this strong support for our reasoning, that the damages due to infringement, which cannot be fully recovered in a regime where backward-looking remedies are relatively unfavorable to the patent holder, determine the plaintiff's preference for a court that provides a fast resolution of the case.

Table 5: Alternative-specific conditional logit model results: court selection I

\begin{tabular}{|c|c|c|c|c|}
\hline Dependent variable: court & (C1) & (C2) & (C3) & (C4) \\
\hline \multicolumn{5}{|l|}{ Alternative-specific variables } \\
\hline Expected length (in months) & $\begin{array}{c}-0.075^{* *} \\
(0.031)\end{array}$ & $\begin{array}{r}-0.048^{*} \\
(0.029)\end{array}$ & $\begin{array}{c}-0.027 \\
(0.026)\end{array}$ & $\begin{array}{c}0.032 \\
(0.036)\end{array}$ \\
\hline Expected length $\times$ Market proximity & & & & $\begin{array}{c}-0.097^{* *} \\
(0.039)\end{array}$ \\
\hline Plaintiff distance to court (in th $\mathrm{km}, \log$ ) & $\begin{array}{c}-0.463^{* * *} \\
(0.044)\end{array}$ & $\begin{array}{c}-0.456^{* * *} \\
(0.046)\end{array}$ & $\begin{array}{c}-0.457^{* * * *} \\
(0.052)\end{array}$ & $\begin{array}{c}-0.458^{* * *} \\
(0.052)\end{array}$ \\
\hline Defendant distance to court (in th $\mathrm{km}, \log$ ) & $\begin{array}{c}-0.279^{* * *} \\
(0.042)\end{array}$ & $\begin{array}{c}-0.290^{* * *} \\
(0.044)\end{array}$ & $\begin{array}{c}-0.288^{* * *} \\
(0.043)\end{array}$ & $\begin{array}{c}-0.284^{* * *} \\
(0.044)\end{array}$ \\
\hline \multicolumn{5}{|l|}{ Case-specific variables: LG Mannheim (MA) } \\
\hline Prior case at court (in last 3 years) & & $\begin{array}{r}-0.255^{*} \\
(0.154)\end{array}$ & $\begin{array}{c}-0.042 \\
(0.167)\end{array}$ & $\begin{array}{c}-0.022 \\
(0.168)\end{array}$ \\
\hline Litigation value (in 100 th $€$ ) & & $\begin{array}{c}-0.047^{* * *} \\
(0.014)\end{array}$ & $\begin{array}{c}-0.034^{* * *} \\
(0.013)\end{array}$ & $\begin{array}{c}-0.034^{* * *} \\
(0.013)\end{array}$ \\
\hline Market proximity & & & & $\begin{array}{c}0.201 \\
(0.159)\end{array}$ \\
\hline \multicolumn{5}{|l|}{ Case-specific variables: LG Munich (MU) } \\
\hline Prior case at court (in last 3 years) & & $\begin{array}{c}-1.618^{* * *} \\
(0.400)\end{array}$ & $\begin{array}{c}-1.248^{* * *} \\
(0.415)\end{array}$ & $\begin{array}{c}-1.256^{\text {*** }} \\
(0.416)\end{array}$ \\
\hline Litigation value (in 100 th $€$ ) & & $\begin{array}{c}-0.117^{* * *} \\
(0.041)\end{array}$ & $\begin{array}{c}-0.094^{* *} \\
(0.041)\end{array}$ & $\begin{array}{c}-0.093^{* *} \\
(0.041)\end{array}$ \\
\hline Market proximity & & & & $\begin{array}{c}0.200 \\
(0.271)\end{array}$ \\
\hline Litigant characteristics & No & No & Yes & Yes \\
\hline Technology effects & Yes & Yes & Yes & Yes \\
\hline Years & Yes & Yes & Yes & Yes \\
\hline Log likelihood & $-1,307.906$ & $-1,250.905$ & $-1,177.879$ & $-1,173.555$ \\
\hline Observations & 5,781 & 5,781 & 5,781 & 5,781 \\
\hline
\end{tabular}

Bootstrapped standard errors in parentheses

${ }^{*} p<0.10,{ }^{* *} p<0.05,{ }^{* * *} p<0.01$

Notes: The sample consists of all patent infringement proceedings based on patents in force and without a (prior) request for a preliminary injunction. The unit of observation is at the case level. Base line regional court: LG Düsseldorf (DU). Control variables as stated in Table B-6. Bootstrapped standard errors with 200 iterations reported.

Concerning the case-specific variables, we find across all specifications robust indications that the courts in Mannheim and Munich are considered less pro-patentee relative to our baseline court in Düsseldorf. We observe a small, yet significant, effect of the litigation value on court selection at the Mannheim regional court, and a larger significant negative effect for the court in Munich, 
with the latter having an almost three times larger effect in magnitude than the former. We see this as empirical support for a perceived anti-patentee bias associated with the Munich regional court and to a smaller extent with the Mannheim regional court. In a similar vein, prior experience with the Munich regional court appears to have a strong negative effect on the decision to revisit the court. These observations are in line with practitioners that confirm heterogeneity in terms of quality, predictability and bias in judicial decision-making among the regional courts - with Düsseldorf most often associated with a patent-friendly profile. ${ }^{47}$

For illustration, we plot the predicted probabilities that a plaintiff selects a particular court against the litigation value of his case (see Figure 4). The higher the litigation value, the more dominant the probability that the case will be heard at the Düsseldorf regional court.

\footnotetext{
${ }^{47}$ There are several professional sources that confirm these results. Interviewed practitioners see judgments in Düsseldorf as most predictable, thanks to the considerable amount of precedent cases and a rather conservative attitude of the judges. While Mannheim is also associated with technical and legal expertise, decisions are argued to be less consistent than in Düsseldorf (Herr and Grunwald, 2011). The frequent churn of judges and the generalist training promoted by inner-court policies at the regional court in Munich is seen to reduce the predictability and quality of decisions (Bornkamm, 2004; Klos, 2010). In addition, judges at the regional court Düsseldorf are commonly associated with a pro-patentee bias compared to other regional courts (Herr and Grunwald, 2011).
} 
Table 6: Alternative-specific conditional logit model results: court selection II

\begin{tabular}{|c|c|c|c|c|}
\hline Dependent variable: court & (C5) & (C6) & $(\mathrm{C} 7)$ & (C8) \\
\hline \multicolumn{5}{|l|}{ Alternative-specific variables } \\
\hline Expected length (in months) & $\begin{array}{c}0.029 \\
(0.037)\end{array}$ & $\begin{array}{c}0.027 \\
(0.037)\end{array}$ & $\begin{array}{c}0.014 \\
(0.046)\end{array}$ & $\begin{array}{c}0.012 \\
(0.045)\end{array}$ \\
\hline Expected length $\times$ Market proximity & $\begin{array}{c}-0.094^{* *} \\
(0.040)\end{array}$ & $\begin{array}{c}-0.093^{* *} \\
(0.040)\end{array}$ & $\begin{array}{c}-0.049 \\
(0.048)\end{array}$ & $\begin{array}{r}-0.047 \\
(0.047)\end{array}$ \\
\hline Expected length $\times$ Litigation value high & & & $\begin{array}{c}0.037 \\
(0.051)\end{array}$ & $\begin{array}{c}0.032 \\
(0.052)\end{array}$ \\
\hline Expected length $\times$ Market proximity $\times$ Litigation value high & & & $\begin{array}{r}-0.118^{*} \\
(0.061)\end{array}$ & $\begin{array}{c}-0.125^{* *} \\
(0.062)\end{array}$ \\
\hline Plaintiff distance to court (in th $\mathrm{km}, \log$ ) & $\begin{array}{c}-0.511^{* * *} \\
(0.073)\end{array}$ & $\begin{array}{c}-0.745^{* * *} \\
(0.099)\end{array}$ & $\begin{array}{c}-0.510^{* * *} \\
(0.074)\end{array}$ & $\begin{array}{c}-0.754^{* * *} \\
(0.100)\end{array}$ \\
\hline Plaintiff distance to court $\times$ Market proximity & $\begin{array}{c}0.109 \\
(0.097)\end{array}$ & $\begin{array}{c}0.141 \\
(0.101)\end{array}$ & $\begin{array}{c}0.101 \\
(0.098)\end{array}$ & $\begin{array}{c}0.131 \\
(0.101)\end{array}$ \\
\hline Plaintiff distance to court $\times$ Plaintiff large & & $\begin{array}{c}0.393^{* * *} \\
(0.106)\end{array}$ & & $\begin{array}{c}0.409^{* * *} \\
(0.106)\end{array}$ \\
\hline Defendant distance to court (in th $\mathrm{km}, \log$ ) & $\begin{array}{c}-0.286^{* * *} \\
(0.059)\end{array}$ & $\begin{array}{c}-0.369^{* * *} \\
(0.076)\end{array}$ & $\begin{array}{c}-0.285^{* * *} \\
(0.060)\end{array}$ & $\begin{array}{c}-0.370^{* * *} \\
(0.077)\end{array}$ \\
\hline Defendant distance to court $\times$ Market proximity & $\begin{array}{c}0.002 \\
(0.092)\end{array}$ & $\begin{array}{c}0.000 \\
(0.094)\end{array}$ & $\begin{array}{c}-0.000 \\
(0.092)\end{array}$ & $\begin{array}{c}-0.004 \\
(0.094)\end{array}$ \\
\hline Defendant distance to court $\times$ Plaintiff large & & $\begin{array}{c}0.158 \\
(0.096)\end{array}$ & & $\begin{array}{c}0.163^{*} \\
(0.097)\end{array}$ \\
\hline \multicolumn{5}{|l|}{ Case-specific variables: LG Mannheim (MA) } \\
\hline Prior case at court (in last 3 years) & $\begin{array}{c}-0.014 \\
(0.169)\end{array}$ & $\begin{array}{c}-0.061 \\
(0.166)\end{array}$ & $\begin{array}{c}0.017 \\
(0.171)\end{array}$ & $\begin{array}{c}-0.028 \\
(0.168)\end{array}$ \\
\hline Litigation value (in 100 th $€$ ) & $\begin{array}{c}-0.034^{* * *} \\
(0.013)\end{array}$ & $\begin{array}{c}-0.034^{* * *} \\
(0.013)\end{array}$ & $\begin{array}{c}-0.038^{* *} \\
(0.017)\end{array}$ & $\begin{array}{c}-0.038^{* *} \\
(0.017)\end{array}$ \\
\hline Market proximity & $\begin{array}{c}0.208 \\
(0.159)\end{array}$ & $\begin{array}{c}0.218 \\
(0.159)\end{array}$ & $\begin{array}{c}0.200 \\
(0.159)\end{array}$ & $\begin{array}{c}0.212 \\
(0.158)\end{array}$ \\
\hline Litigation value high & & & $\begin{array}{c}-0.083 \\
(0.217)\end{array}$ & $\begin{array}{c}-0.109 \\
(0.216)\end{array}$ \\
\hline \multicolumn{5}{|l|}{ Case-specific variables: LG Munich (MU) } \\
\hline Prior case at court (in last 3 years) & $\begin{array}{c}-1.219^{* * *} \\
(0.418)\end{array}$ & $\begin{array}{c}-1.069^{* * *} \\
(0.402)\end{array}$ & $\begin{array}{c}-1.240^{* * *} \\
(0.429)\end{array}$ & $\begin{array}{c}-1.088^{* * *} \\
(0.414)\end{array}$ \\
\hline Litigation value (in 100 th $€$ ) & $\begin{array}{c}-0.092^{* *} \\
(0.040)\end{array}$ & $\begin{array}{c}-0.095^{* *} \\
(0.040)\end{array}$ & $\begin{array}{c}-0.079 \\
(0.050)\end{array}$ & $\begin{array}{r}-0.080^{*} \\
(0.048)\end{array}$ \\
\hline Market proximity & $\begin{array}{c}0.248 \\
(0.278)\end{array}$ & $\begin{array}{c}0.282 \\
(0.284)\end{array}$ & $\begin{array}{c}0.256 \\
(0.288)\end{array}$ & $\begin{array}{c}0.289 \\
(0.294)\end{array}$ \\
\hline Litigation value high & & & $\begin{array}{c}0.236 \\
(0.381)\end{array}$ & $\begin{array}{c}0.280 \\
(0.387)\end{array}$ \\
\hline Litigant characteristics & Yes & Yes & Yes & Yes \\
\hline Technology effects & Yes & Yes & Yes & Yes \\
\hline Years & Yes & Yes & Yes & Yes \\
\hline Log likelihood & -564.167 & -527.459 & -134.632 & -347.697 \\
\hline Observations & 5,781 & 5,781 & 5,781 & 5,781 \\
\hline
\end{tabular}

Bootstrapped standard errors in parentheses

${ }^{*} p<0.10,{ }^{* *} p<0.05,{ }^{* * *} p<0.01$

Notes: The sample consists of all patent infringement proceedings without a (prior) request for a preliminary injunction. The unit of observation is at the case level. Base line regional court: LG Düsseldorf (DU). Litigation value high defined as Litigation value $\geq 500$ th $€$. Control variables as stated in Table B-6. Bootstrapped standard errors with 200 iterations reported. 
Figure 4: Predicted probabilities for each court selection by litigation value

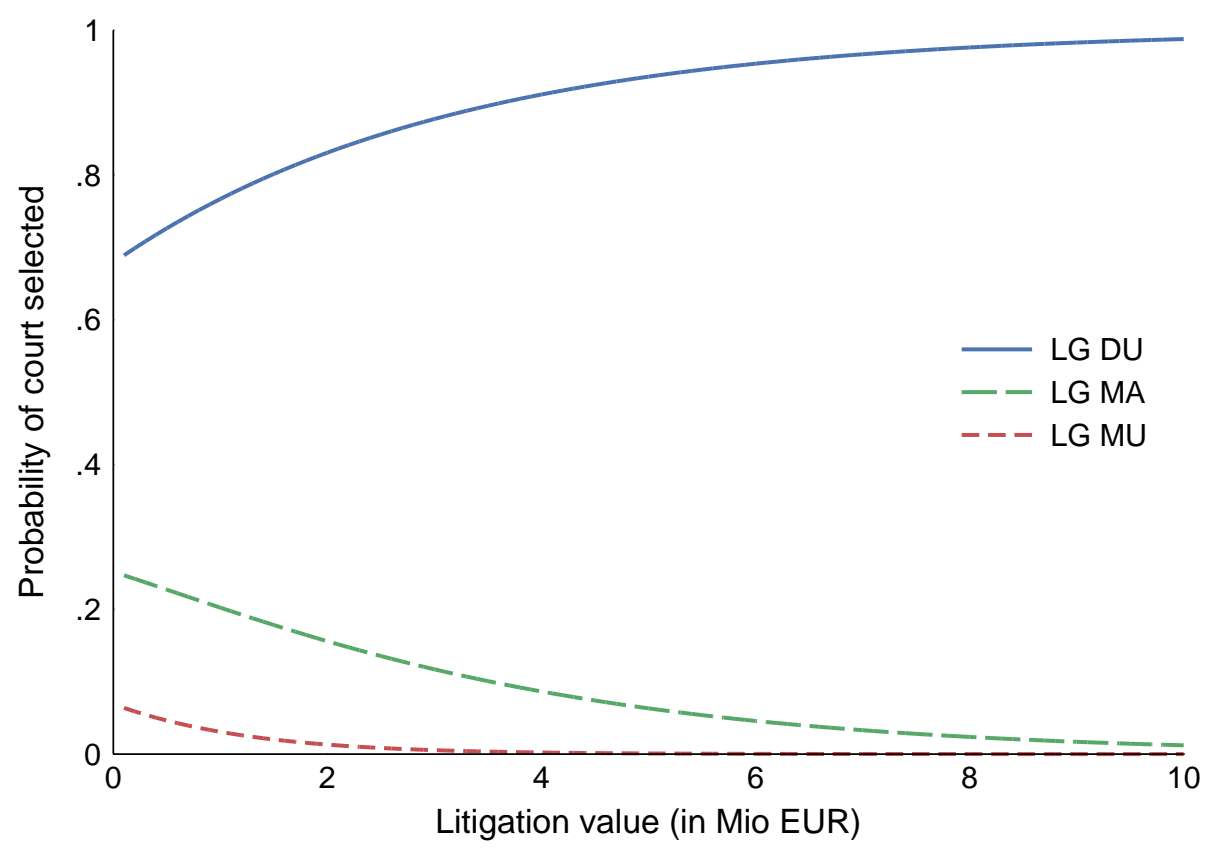

Notes: Predictions on baseline model (C4). All covariates estimated at their mean. Truncated at $€ 10$ Mio.

\subsection{Robustness}

To show robustness of our results and to exclude the possibility that the observed effects are driven by the nationality and the location of the litigants, we regress our baseline specification (C4) on four subsamples (see Table B-7 in the Appendix). As mentioned, some courts show a strong concentration of cases from a particular country (e.g., Japanese firms hearing their cases almost exclusively in Düsseldorf). We therefore exclude defendants and plaintiffs from outside of Europe (column (C9) and column (C10) - the results remain robust. Furthermore, the requirements for territorial jurisdiction at all courts may not be met in all cases within our sample. ${ }^{48}$ This would result in an overestimation of the effect of the defendant's distance to court on court selection. That is, the latter could be a corollary of the fact that only the defendant's residence fulfills the requirements for territorial jurisdiction (cf. Section 3.1). In column (C11) we remove cases where the plaintiff or the defendant resides within the jurisdiction of any of the three courts. We do so by excluding cases where the respective party resides closer than $150 \mathrm{~km}$ to at least one of the there regional courts. While losing some significance due to the reduced sample, all main effects remain constant in their magnitude.

\footnotetext{
${ }^{48}$ Even though we take special care to exclude proceedings with a trade fare context and/or a (prior) request for preliminary injunction in our main sample.
} 


\section{Discussion and Conclusion}

There is considerable disagreement among scholars concerning the welfare effects of forum shopping. Proponents link a positive effect of forum shopping to the invisible hand argument: the plaintiff's free choice among multiple courts leads to efficiency gains in the market for litigation. That is, courts, facing institutional competition, have an incentive to invest in specialization, accrue experience and induce procedural innovations to attract patent disputes, whereas plaintiffs are able to avoid congested dockets and courts lacking expertise in the patent's underlying technology (Moore, 2001b). Opponents of forum shopping, however, argue that free court selection may lead to systematic partiality in judicial decision making if one side in litigation, i.e., the plaintiff, dominates the decision on court selection. Legal scholars recently coined the term forum selling as the supply-side equivalent to forum shopping, referring to a court's leaning to decide pro-plaintiff to attract more cases (Klerman and Reilly, 2014). Leaving fairness arguments aside, lack of uniformity in judicial decision-making may increase legal uncertainty and ultimately result in fewer settlements (Galasso and Schankerman, 2010).

One reason for this academic disagreement may be found in the lack of clarity regarding the court selection problem of plaintiffs and how it depends on particular aspects of the litigation regime. In this study we investigated theoretically and empirically the determinants of court selection in patent litigation. We assumed that courts differ in litigation costs, pro-patentee bias, and length of proceeding. As shown in the theoretical model, if and how litigation costs and the length of proceeding affect court preferences depend on available remedies and cost allocation rules. In line with the theoretical predictions for Germany, typically identified as a regime with more favorable forward-looking remedies, we find that speedy enforcement is highly valued if the litigants operate in the same product market. This effect may turn out beneficial for the overall functioning of the judicial system. First, the self-allocation of patent disputes among multiple courts can lead to efficiency gains. In order to attract suitable patent cases, courts have an incentive to provide fast decisions. Second, as speed is also a function of a court's caseload, one may argue for a countervailing effect to excessive case concentration, as popular courts will lose attraction with an increasing number of filed cases. However, as shown in the theoretical model, this reverse effect should be less pronounced in regimes with more favorable backward-looking remedies. ${ }^{49}$

We also find that court-specific litigation costs, empirically captured by the distance of the litigants to a particular court, have a negative effect on the plaintiff's court selection. Here, the magnitude of the effect is considerably larger for small plaintiffs. If small plaintiffs are particularly sensitive to litigation costs, they may be reluctant to file their action in the first place due to overwhelming litigation costs in judicial systems that force them to seek judicial relief at a distant court. This sets limits to the virtue of alternative designs for judicial systems that could obstruct court competition, such as centralization, i.e., a single court hears all cases, or randomization, i.e., allocation of cases

\footnotetext{
${ }^{49}$ In fact, the popularity of the District Court in the Eastern District of Texas, which hears by far the most patent cases in the U.S., can hardly be linked to fast case resolution and has remained stable despite an ever-increasing caseload (Love and Yoon, 2016).
} 
to courts is taken out of the litigants' hands, since both designs likely increase litigation costs and disadvantage small firms on either side. Hence, a combination of restricting choice of venue and stipulating cost allocation rules that deter litigants to raise the opposite side's litigation costs may be the preferred option. 


\section{References}

Ann, C. (2009). Verletzungsgerichtsbarkeit zentral für jedes Patentsystem und doch häufig unterschätzt. GRUR - Gewerblicher Rechtsschutz und Urheberrecht 111(3/4), 205-209.

Atkinson, S. E., A. C. Marco, and J. L. Turner (2009). The Economics of a Centralized Judiciary: Uniformity, Forum Shopping, and the Federal Circuit. Journal of Law and Economics 52(3), 411443.

Bornkamm, J. (2004). Intellectual Property Litigation under the Civil Law Legal System: Experience in Germany. In WIPO Advisory Comittee on Enforcement, Geneva.

Cabrillo, F. and S. Fitzpatrick (2008). The Economics of Courts and Litigation (1st ed.). Edward Elgar Publishing.

Cohen, L., U. G. Gurun, and S. D. Kominers (2016). The Growing Problem of Patent Trolling. Science 352(6285), 521-522.

Cohen, W. M., R. R. Nelson, and J. P. Walsh (2000). Protecting Their Intellectual Property Assets: Appropriability Conditions and Why U.S. Manufacturing Firms Patent (or Not). NBER Working Paper 7552.

Cotter, T. F. (2013). Comparative Patent Remedies: A Legal and Economic Analysis (1st ed.). Oxford University Press, Oxford.

Crampes, C. and C. Langinier (2002). Litigation and Settlement in Patent Infringement Cases. The RAND Journal of Economics 33(2), 258-274.

Cremers, K., M. Ernicke, F. Gaessler, D. Harhoff, C. Helmers, L. McDonagh, P. Schliessler, and N. van Zeebroeck (2016). Patent Litigation in Europe. European Journal of Law and Economics (forthcoming), 1-44.

Cremers, K., F. Gaessler, D. Harhoff, C. Helmers, and Y. Lefouili (2016). Invalid but Infringed? An Analysis of the Bifurcated Patent Litigation System. Journal of Economic Behavior \& Organization 131, 218-242.

Encaoua, D. and Y. Lefouili (2009). Licensing "Weak" Patents. The Journal of Industrial Economics 57(3), 492-525.

Farrell, J. and C. Shapiro (2008). How Strong Are Weak Patents? American Economic Review 98(4), 1347-1369.

Friedman, A. (2016). Damages Control: Returning Royalties to their Reasonable Roots. The John Marshall Review of Intellectual Property Law 15, 827-845.

Galasso, A. and M. Schankerman (2010). Patent Thickets, Courts, and the Market for Innovation. The RAND Journal of Economics 41(3), 472-503.

Harguth, A. and S. C. Carlson (2011). Patents in Germany and Europe, Procurement, Enforcement and Defence: An International Handbook (1st ed.). Kluwer Law International.

Helmers, C., L. McDonagh, and B. Love (2014). Is There a Patent Troll Problem in the UK? Fordham Intellectual Property, Media \& Entertainment Law Journal 24, 509-553. 
Herr, J. and M. Grunwald (2011). Speedy Patent Infringement Proceedings in Germany: Pros and Cons of the Go-To Courts. Journal of Intellectual Property Law \& Practice 7(1), 44-47.

Kesan, J. P. and G. G. Ball (2011). Judicial Experience and the Efficiency and Accuracy of Patent Adjudication: An Empirical Analysis of the Case for a Specialized Patent Trial Court. Harvard Journal of Law \& Technology 24(2), 393-467.

Klerman, D. M. and G. Reilly (2014). Forum Selling. USC Law Legal Studies Paper No. 14-44.

Klos, M. (2010). Standortvorurteil. JUVE Rechtsmarkt 4(12), 72-83.

Kühnen, T. (2012). Patent Litigation Proceedings in Germany: A Handbook for Practitioners (6th ed.). translated by Frank Peterreins, Carl Heymanns Verlag.

Lanjouw, J. O. and M. Schankerman (2001). Characteristics of Patent Litigation: A Window on Competition. The RAND Journal of Economics 32(1), 129-151.

Lemley, M. A. (2009). Distinguishing Lost Profits from Reasonable Royalties. William and Mary Law Review 51(2), 655-674.

Lemley, M. A. (2010). Where to File Your Patent Case. AIPLA Quarterly Journal 38(4), 401-436.

Lerner, J. and J. Tirole (2006). A Model of Forum Shopping. The American Economic Review 96(4), 1091-1113.

Lii, T. (2013). Shopping for Reversals: How Accuracy Differs across Patent Litigation Forums. The Chicago-Kent Journal of Intellectual Property 12, 31-51.

Love, B. J. and J. C. Yoon (2016). Predictably Expensive: A Critical Look at Patent Litigation in the Eastern District of Texas.

McKelvie, R. R. (2007). Forum Selection in Patent Litigation: A Traffic Report. Intellectual Property \& Technology Law Journal 19, 1-17.

Moore, K. A. (2001a). Are District Court Judges Equipped to Resolve Patent Cases? Harvard Journal of Law \& Technology 15(1), 1-39.

Moore, K. A. (2001b). Forum Shopping in Patent Cases: Does Geographic Choice Affect Innovation? North Carolina Law Review 79, 889-938.

Müller-Stoy, T. and T. Schachl (2011). LG München I macht Lizenzanalogie attraktiver. GRUR-PraxGewerblicher Rechtsschutz und Urheberrecht, Praxis im Immaterialgüter- und Wettbewerbs-recht 3, 341-343.

Ozimek, A. and D. Miles (2011). Stata Utilities for Geocoding and Generating Travel Time and Travel Distance Information. The Stata Journal 11(1), 106-119.

Pitz, J. and G. Hermann (2005). Interplay between Opposition Proceedings and Patent Litigation. www.buildingipvalue.com/05_EU/233_236.htm [accessed: 7 January 2015].

Reitzig, M., J. Henkel, and C. Heath (2007). On Sharks, Trolls, and Their Patent Prey - Unrealistic Damage Awards and Frms' Strategies of "Being Infringed". Research Policy 36(1), 134-154.

Schankerman, M. and S. Scotchmer (2001). Damages and Injunctions in Protecting Intellectual Property. The RAND Journal of Economics 32(1), 199-220. 
Shapiro, C. (2016). Patent Remedies. American Economic Review: Papers and Proceedings 106(5), 198-202.

Shapiro, C. (2017). Property Rules vs. Liability Rules in Patent Infringement.

von Mehren, A. T. (1983). Adjudicatory Jurisdiction: General Theories Compared and Evaluated. Boston University Law Review 63(2), 279-340.

Wadlow, C. (2015). An Historical Perspective II: The Unified Patent Court. In J. Pila and C. Wadlow (Eds.), The Unitary EU Patent System (1st ed.)., Chapter 3, pp. 33-44. Hart Publishing, Oxford. 


\section{A Appendix: Figures}

Figure A-1: Court structure in Germany's patent system (Cremers et al., 2016a, amended)

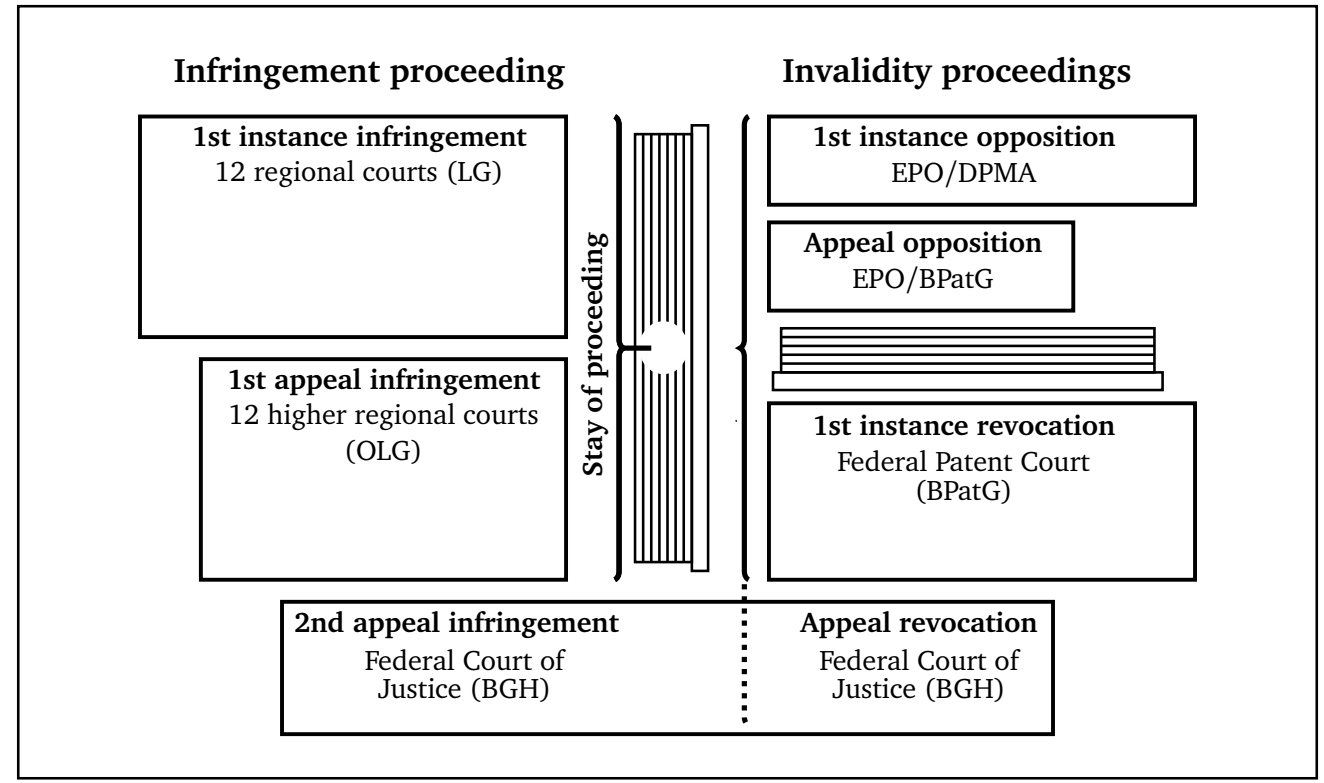

Figure A-2: Proceedings linked to patent infringement disputes (own illustration)

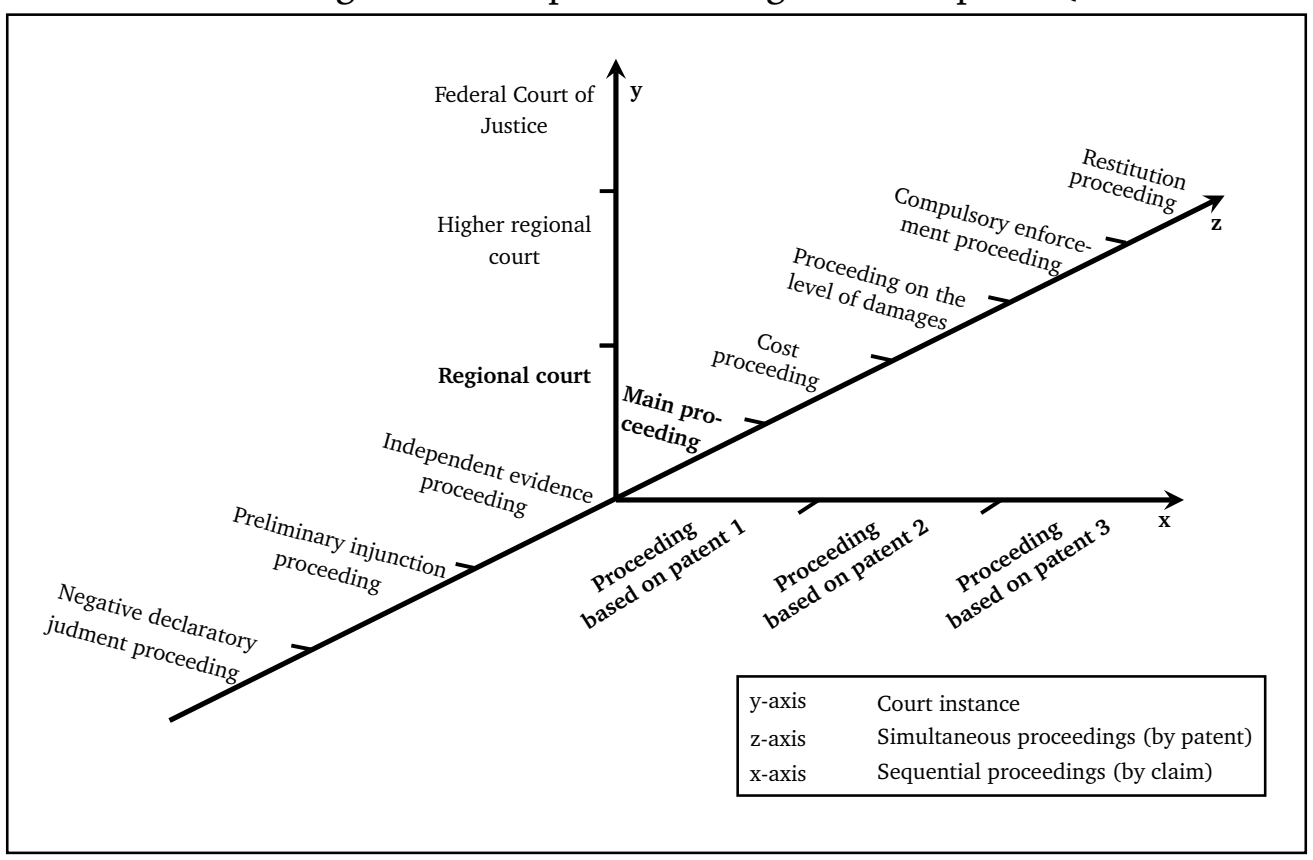


Figure A-3: Structure of the infringement main proceeding (own illustration)

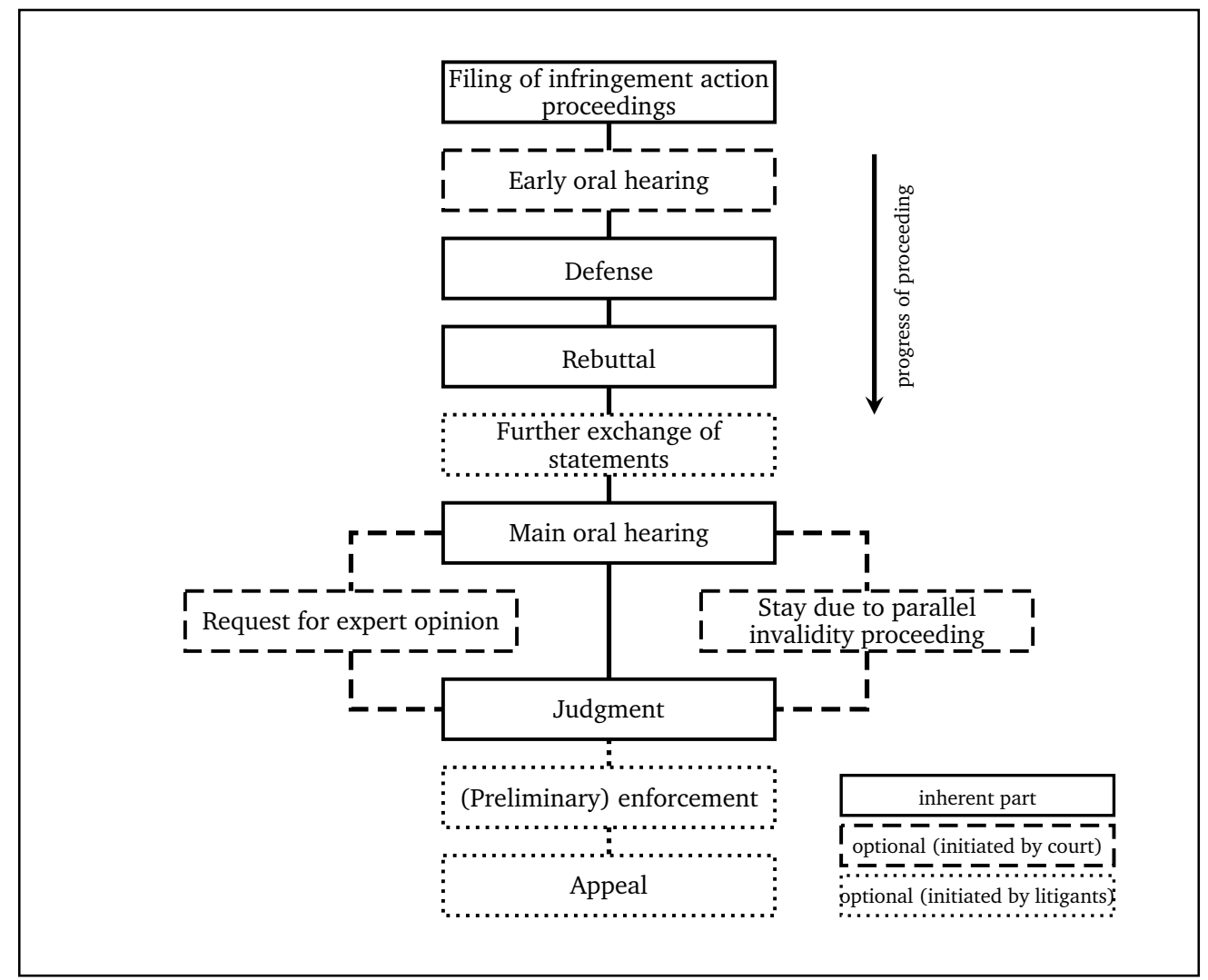




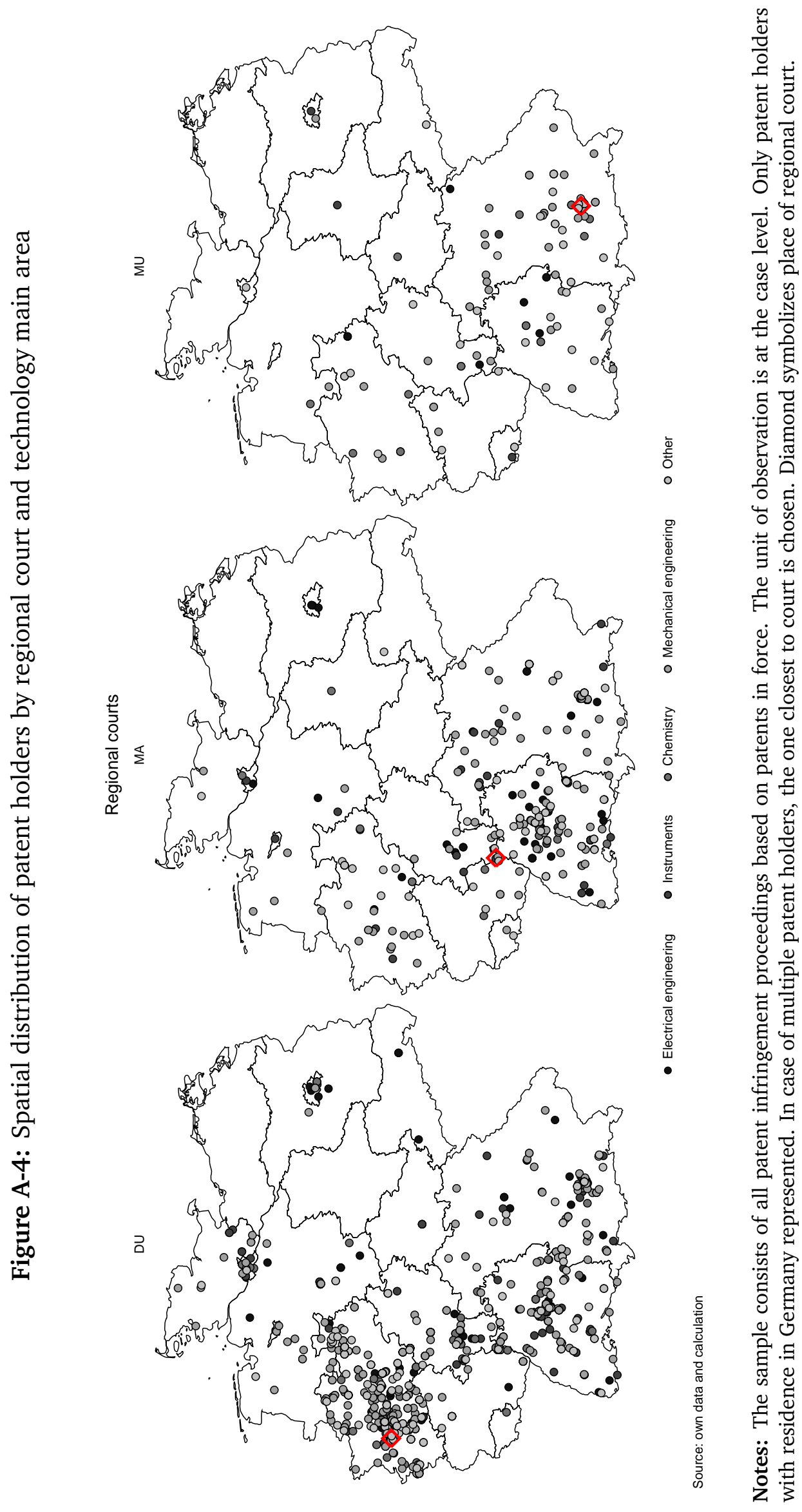




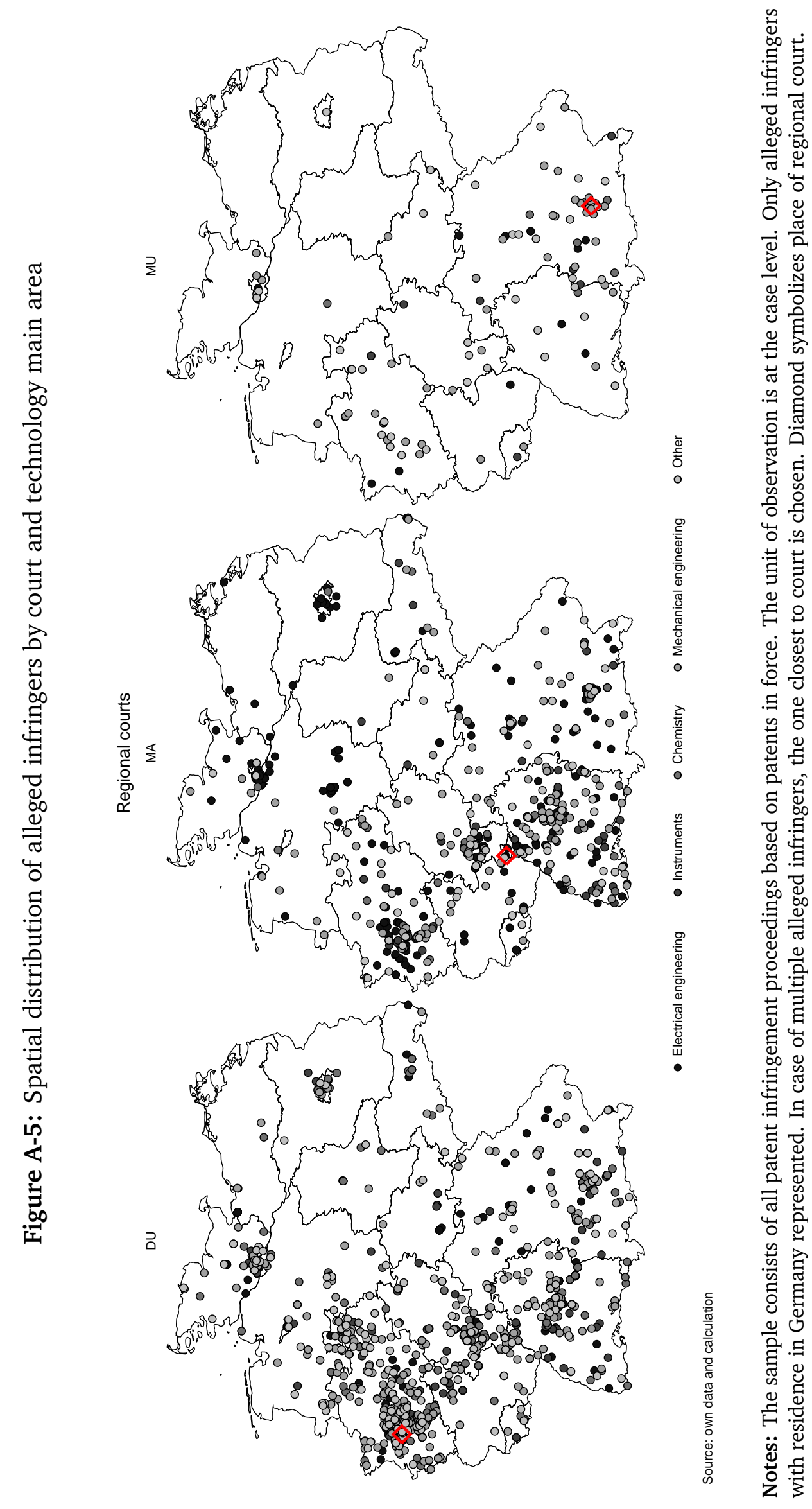




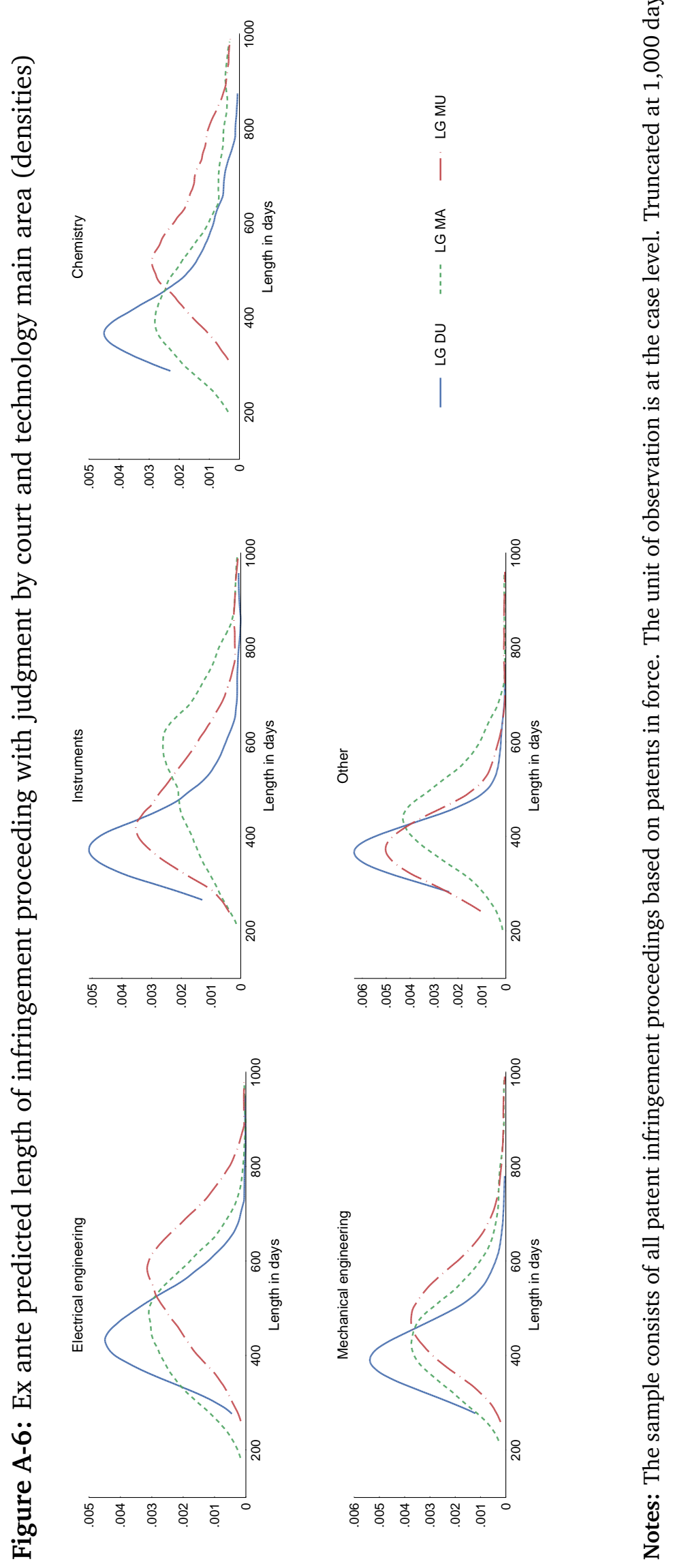




\section{B Appendix: Tables}

Table B-1: Summary statistics grouped by regional court

\begin{tabular}{|c|c|c|c|c|c|c|c|c|c|}
\hline \multirow{4}{*}{ Courts } & \multicolumn{9}{|c|}{ Regional court } \\
\hline & \multicolumn{3}{|c|}{ LG DU } & \multicolumn{3}{|c|}{ LG MA } & \multicolumn{3}{|c|}{ LG MU } \\
\hline & \multicolumn{2}{|c|}{ Mean Min } & \multirow[t]{2}{*}{ Max } & \multicolumn{2}{|c|}{ Mean Min } & \multirow[t]{2}{*}{ Max } & \multirow{2}{*}{\multicolumn{2}{|c|}{ Mean Min }} & \multirow[t]{2}{*}{ Max } \\
\hline & & & & & & & & & \\
\hline Litigation value (in th $€$ ) & $1,093.41$ & \multicolumn{2}{|c|}{130,000} & 419.86 & \multicolumn{3}{|c|}{$016,500333.64$} & \multicolumn{2}{|c|}{53,500} \\
\hline Length of proceeding (in months) & 13.18 & 0 & 123 & 10.70 & 0 & 88 & 12.20 & & 78 \\
\hline Parallel opposition proceeding (d) & 0.17 & 0 & 1 & 0.12 & 0 & 1 & 0.09 & 0 & 1 \\
\hline Parallel revocation proceeding (d) & 0.32 & 0 & 1 & 0.49 & 0 & 1 & 0.28 & 0 & 1 \\
\hline - infringement proc. stayed (d) & 0.18 & 0 & 1 & 0.18 & 0 & 1 & 0.30 & 0 & 1 \\
\hline Expert opinion $(d)$ & 0.08 & 0 & 1 & 0.12 & 0 & 1 & 0.20 & 0 & 1 \\
\hline Preliminary injunction (d) & 0.21 & 0 & 1 & 0.10 & 0 & 1 & 0.27 & 0 & 1 \\
\hline Multi-jurisdictional litigation (d) & 0.03 & 0 & 1 & 0.01 & 0 & 1 & 0.02 & 0 & 1 \\
\hline \multicolumn{10}{|l|}{ Judges } \\
\hline Tenure as judge (in years) & 11.80 & 7 & 16 & 15.68 & 2 & 25 & 22.05 & 15 & 30 \\
\hline Prior exposure to technology area & 5.10 & 3 & 6 & 4.04 & 1 & 5 & 2.77 & 0 & 4 \\
\hline \multicolumn{10}{|l|}{ Patent holder } \\
\hline Nonpracticing entity (d) & 0.11 & 0 & 1 & 0.46 & 0 & 1 & 0.27 & 0 & 1 \\
\hline Micro $(d)$ & 0.09 & 0 & 1 & 0.13 & 0 & 1 & 0.24 & 0 & 1 \\
\hline Small (d) & 0.10 & 0 & 1 & 0.08 & 0 & 1 & 0.11 & 0 & 1 \\
\hline Medium (d) & 0.16 & 0 & 1 & 0.14 & 0 & 1 & 0.18 & 0 & 1 \\
\hline Large (d) & 0.65 & 0 & 1 & 0.65 & 0 & 1 & 0.47 & 0 & 1 \\
\hline Germany (d) & 0.47 & 0 & 1 & 0.40 & 0 & 1 & 0.62 & 0 & 1 \\
\hline Europe (excl. Germany) (d) & 0.28 & 0 & 1 & 0.53 & 0 & 1 & 0.29 & 0 & 1 \\
\hline World (excl. Europe) (d) & 0.25 & 0 & 1 & 0.07 & 0 & 1 & 0.09 & 0 & 1 \\
\hline Distance to court (in th $\mathrm{km}$ ) & 2.13 & 0 & 17 & 0.92 & 0 & 9 & 1.13 & 0 & 9 \\
\hline Top legal representative (no. of cases) (d) & 0.89 & 0 & 1 & 0.79 & 0 & 1 & 0.61 & 0 & 1 \\
\hline \multicolumn{10}{|l|}{ Alleged infringer } \\
\hline Micro (d) & 0.09 & 0 & 1 & 0.24 & 0 & 1 & 0.18 & 0 & 1 \\
\hline Small (d) & 0.15 & 0 & 1 & 0.17 & 0 & 1 & 0.27 & 0 & 1 \\
\hline Medium (d) & 0.25 & 0 & 1 & 0.25 & 0 & 1 & 0.24 & 0 & 1 \\
\hline Large $(d)$ & 0.51 & 0 & 1 & 0.33 & 0 & 1 & 0.31 & 0 & 1 \\
\hline Germany (d) & 0.72 & 0 & 1 & 0.81 & 0 & 1 & 0.66 & 0 & 1 \\
\hline Europe (excl. Germany) (d) & 0.19 & 0 & 1 & 0.09 & 0 & 1 & 0.19 & 0 & 1 \\
\hline World (excl. Europe) (d) & 0.08 & 0 & 1 & 0.10 & 0 & 1 & 0.14 & 0 & 1 \\
\hline Distance to court (in th $\mathrm{km}$ ) & 0.94 & 0 & 17 & 1.12 & 0 & 15 & 1.65 & 0 & 12 \\
\hline Top legal representative (no. of cases) (d) & 0.78 & 0 & 1 & 0.63 & 0 & 1 & 0.70 & 0 & 1 \\
\hline Product market proximity & 0.70 & 0 & 1 & 0.47 & 0 & 1 & 0.60 & 0 & 1 \\
\hline \multicolumn{10}{|l|}{ Patent characteristics } \\
\hline PCT filing (d) & 0.28 & 0 & 1 & 0.16 & 0 & 1 & 0.25 & 0 & 1 \\
\hline$E P$ bundle patent (d) & 0.81 & 0 & 1 & 0.79 & 0 & 1 & 0.75 & 0 & 1 \\
\hline Accelerated examination requested (d) & 0.19 & 0 & 1 & 0.12 & 0 & 1 & 0.21 & 0 & 1 \\
\hline Size of DOCDB family & 10.96 & 1 & 183 & 28.54 & 1 & 69 & 14.31 & 1 & 69 \\
\hline
\end{tabular}




\begin{tabular}{|c|c|c|c|c|c|c|c|c|c|}
\hline \multirow[b]{2}{*}{ Age of patent (in years) } & \multicolumn{3}{|c|}{ LG DU } & \multicolumn{3}{|c|}{ LG MA } & \multicolumn{3}{|c|}{ LG MU } \\
\hline & 11.86 & 2 & 25 & 12.86 & 2 & 23 & 11.04 & 2 & 22 \\
\hline IPC subclass count & 2.05 & 1 & 11 & 4.31 & 1 & 9 & 2.69 & 1 & 9 \\
\hline Forward citations (in first 3 years) & 3.14 & 0 & 51 & 6.66 & 0 & 41 & 3.22 & 0 & 15 \\
\hline Backward citations (patents) & 5.12 & 0 & 32 & 5.78 & 0 & 33 & 5.12 & 1 & 27 \\
\hline Backward citations (nonpatent literature) & 0.88 & 0 & 41 & 1.94 & 0 & 21 & 1.03 & 0 & 21 \\
\hline Prior infringement decision on patent (d) & 0.10 & 0 & 1 & 0.07 & 0 & 1 & 0.12 & 0 & 1 \\
\hline \multicolumn{10}{|l|}{ Patent technology area } \\
\hline Chemistry (d) & 0.18 & 0 & 1 & 0.07 & 0 & 1 & 0.10 & 0 & 1 \\
\hline Electrical engineering (d) & 0.25 & 0 & 1 & 0.49 & 0 & 1 & 0.24 & 0 & 1 \\
\hline Instruments $(\mathrm{d})$ & 0.12 & 0 & 1 & 0.08 & 0 & 1 & 0.07 & 0 & 1 \\
\hline Mechanical engineering (d) & 0.30 & 0 & 1 & 0.21 & 0 & 1 & 0.30 & 0 & 1 \\
\hline Other $(d)$ & 0.16 & 0 & 1 & 0.14 & 0 & 1 & 0.29 & 0 & 1 \\
\hline \multicolumn{10}{|l|}{ Patent invalidation history } \\
\hline Patent solidified (opposition proc.) (d) & 0.15 & 0 & 1 & 0.09 & 0 & 1 & 0.16 & 0 & 1 \\
\hline Patent challenged (revocation proc.) (d) & 0.08 & 0 & 1 & 0.34 & 0 & 1 & 0.16 & 0 & 1 \\
\hline Patent solidified (revocation proc.) (d) & 0.02 & 0 & 1 & 0.02 & 0 & 1 & 0.03 & 0 & 1 \\
\hline $\mathrm{N}$ & \multicolumn{3}{|c|}{1,719} & \multicolumn{3}{|c|}{692} & \multicolumn{3}{|c|}{188} \\
\hline
\end{tabular}

Notes: The sample consists of all patent infringement proceedings without preliminary injunctions. The unit of observation is the infringement proceeding. 
Table B-2: Statistics of litigation value by court and technology main area

\begin{tabular}{|c|c|c|c|c|c|}
\hline \multirow[b]{2}{*}{ Regional court } & \multicolumn{5}{|c|}{ Litigation value (in thousand $€$ ) } \\
\hline & Mean & Median & Std. dev. & Min & Max \\
\hline \multicolumn{6}{|c|}{ Electrical engineering } \\
\hline LG DU & $1,809.80$ & $1,500.00$ & $1,768.64$ & 2 & 15,000 \\
\hline LG MA & 297.44 & 50.00 & 696.70 & 0 & 9,000 \\
\hline LG MU & 242.15 & 85.00 & 531.76 & 5 & 3,500 \\
\hline \multicolumn{6}{|l|}{ Instruments } \\
\hline LG DU & $1,012.78$ & 500.00 & $1,917.48$ & 4 & 18,000 \\
\hline LG MA & 760.85 & 450.00 & $1,171.50$ & 12 & 5,000 \\
\hline LG MU & 373.77 & 250.00 & 394.21 & 39 & 1,500 \\
\hline \multicolumn{6}{|l|}{ Chemistry } \\
\hline LG DU & $1,288.44$ & 800.00 & $2,339.10$ & 38 & 30,000 \\
\hline LG MA & 899.68 & 500.00 & $2,392.97$ & 10 & 16,500 \\
\hline LG MU & 505.83 & 275.00 & 517.00 & 50 & 2,000 \\
\hline \multicolumn{6}{|c|}{ Mechanical engineering } \\
\hline LG DU & 684.35 & 500.00 & 969.71 & 1 & 10,000 \\
\hline LG MA & 491.06 & 500.00 & 503.94 & 7 & 5,000 \\
\hline LG MU & 403.07 & 275.00 & 443.40 & 5 & 2,000 \\
\hline \multicolumn{6}{|l|}{ Other } \\
\hline LG DU & 606.16 & 300.00 & 978.90 & 2 & 10,000 \\
\hline LG MA & 317.40 & 250.00 & 296.64 & 2 & 1,534 \\
\hline LG MU & 270.70 & 180.00 & 309.89 & 20 & 2,000 \\
\hline All & 859.12 & 500.00 & $1,485.07$ & 1 & 30,000 \\
\hline
\end{tabular}

Notes: The sample consists of all patent infringement proceedings. The unit of observation is at the case level. 
Table B-3: Residence countries of litigants by court

\begin{tabular}{|c|c|c|c|c|c|c|c|c|}
\hline \multirow[b]{3}{*}{ Country } & \multicolumn{6}{|c|}{ Regional court } & & \\
\hline & \multicolumn{2}{|c|}{ LG DU } & \multicolumn{2}{|c|}{ LG MA } & \multicolumn{2}{|c|}{ LG MU } & \multicolumn{2}{|c|}{ Total } \\
\hline & $\mathrm{N}$ & $\%$ & $\mathrm{~N}$ & $\%$ & $\mathrm{~N}$ & $\%$ & $\mathrm{~N}$ & $\%$ \\
\hline \multicolumn{9}{|c|}{$\begin{array}{l}\text { Patent holders } \\
\text { European }\end{array}$} \\
\hline AT & 41 & $2.4 \%$ & 14 & $2.0 \%$ & 3 & $1.6 \%$ & 58 & $2.2 \%$ \\
\hline $\mathrm{BE}$ & 18 & $1.0 \%$ & 2 & $0.3 \%$ & 0 & $0.0 \%$ & 20 & $0.8 \%$ \\
\hline $\mathrm{CH}$ & 84 & $4.9 \%$ & 26 & $3.8 \%$ & 7 & $3.7 \%$ & 117 & $4.5 \%$ \\
\hline DE & 812 & $47.2 \%$ & 279 & $40.3 \%$ & 117 & $62.2 \%$ & 1208 & $46.5 \%$ \\
\hline DK & 32 & $1.9 \%$ & 2 & $0.3 \%$ & 1 & $0.5 \%$ & 35 & $1.3 \%$ \\
\hline FR & 73 & $4.2 \%$ & 16 & $2.3 \%$ & 11 & $5.9 \%$ & 100 & $3.8 \%$ \\
\hline IE & 11 & $0.6 \%$ & 4 & $0.6 \%$ & 1 & $0.5 \%$ & 16 & $0.6 \%$ \\
\hline IT & 53 & $3.1 \%$ & 250 & $36.1 \%$ & 23 & $12.2 \%$ & 326 & $12.5 \%$ \\
\hline NL & 93 & $5.4 \%$ & 31 & $4.5 \%$ & 0 & $0.0 \%$ & 124 & $4.8 \%$ \\
\hline NO & 12 & $0.7 \%$ & 0 & $0.0 \%$ & 0 & $0.0 \%$ & 12 & $0.5 \%$ \\
\hline SE & 29 & $1.7 \%$ & 11 & $1.6 \%$ & 4 & $2.1 \%$ & 44 & $1.7 \%$ \\
\hline UK & 51 & $3.0 \%$ & 4 & $0.6 \%$ & 5 & $2.7 \%$ & 60 & $2.3 \%$ \\
\hline Other & 21 & $1.2 \%$ & 10 & $1.4 \%$ & 0 & $0.0 \%$ & 31 & $1.2 \%$ \\
\hline \multicolumn{9}{|c|}{ Non-European } \\
\hline IL & 23 & $1.3 \%$ & 3 & $0.4 \%$ & 0 & $0.0 \%$ & 26 & $1.0 \%$ \\
\hline JP & 170 & $9.9 \%$ & 5 & $0.7 \%$ & 8 & $4.3 \%$ & 183 & $7.0 \%$ \\
\hline US & 174 & $10.1 \%$ & 32 & $4.6 \%$ & 4 & $2.1 \%$ & 210 & $8.1 \%$ \\
\hline Other & 22 & $1.0 \%$ & 3 & $0.4 \%$ & 4 & $2.1 \%$ & 29 & $1.1 \%$ \\
\hline Total & 1,719 & $100.0 \%$ & 692 & $100.0 \%$ & 188 & $100.0 \%$ & 2,599 & $100.0 \%$ \\
\hline
\end{tabular}

Alleged infringers

European

\begin{tabular}{|c|c|c|c|c|c|c|c|c|}
\hline AT & 27 & $1.6 \%$ & 9 & $1.3 \%$ & 2 & $1.1 \%$ & 38 & $1.5 \%$ \\
\hline $\mathrm{BE}$ & 19 & $1.1 \%$ & 0 & $0.0 \%$ & 0 & $0.0 \%$ & 19 & $0.7 \%$ \\
\hline $\mathrm{CH}$ & 17 & $1.0 \%$ & 6 & $0.9 \%$ & 2 & $1.1 \%$ & 25 & $1.0 \%$ \\
\hline $\mathrm{CZ}$ & 14 & $0.8 \%$ & 0 & $0.0 \%$ & 1 & $0.5 \%$ & 15 & $0.6 \%$ \\
\hline $\mathrm{DE}$ & 1242 & $72.3 \%$ & 563 & $81.4 \%$ & 125 & $66.5 \%$ & 1930 & $74.3 \%$ \\
\hline DK & 12 & $0.7 \%$ & 0 & $0.0 \%$ & 0 & $0.0 \%$ & 12 & $0.5 \%$ \\
\hline $\mathrm{ES}$ & 15 & $0.9 \%$ & 7 & $1.0 \%$ & 12 & $6.4 \%$ & 34 & $1.3 \%$ \\
\hline FR & 54 & $3.1 \%$ & 5 & $0.7 \%$ & 3 & $1.6 \%$ & 62 & $2.4 \%$ \\
\hline IT & 63 & $3.7 \%$ & 15 & $2.2 \%$ & 9 & $4.8 \%$ & 87 & $3.3 \%$ \\
\hline NL & 31 & $1.8 \%$ & 9 & $1.3 \%$ & 2 & $1.1 \%$ & 42 & $1.6 \%$ \\
\hline PL & 21 & $1.2 \%$ & 3 & $0.4 \%$ & 0 & $0.0 \%$ & 24 & $0.9 \%$ \\
\hline SE & 10 & $0.6 \%$ & 0 & $0.0 \%$ & 1 & $0.5 \%$ & 11 & $0.4 \%$ \\
\hline TR & 6 & $0.3 \%$ & 4 & $0.6 \%$ & 1 & $0.5 \%$ & 11 & $0.4 \%$ \\
\hline UK & 48 & $2.8 \%$ & 2 & $0.3 \%$ & 1 & $0.5 \%$ & 51 & $2.0 \%$ \\
\hline Other & 23 & $1.3 \%$ & 3 & $0.4 \%$ & 1 & $0.5 \%$ & 28 & $1.1 \%$ \\
\hline \multicolumn{9}{|c|}{ Non-European } \\
\hline $\mathrm{CN}$ & 52 & $3.0 \%$ & 18 & $2.6 \%$ & 9 & $4.8 \%$ & 79 & $3.0 \%$ \\
\hline HK & 10 & $0.6 \%$ & 16 & $2.3 \%$ & 1 & $0.5 \%$ & 27 & $1.0 \%$ \\
\hline $\mathrm{KR}$ & 11 & $0.6 \%$ & 7 & $1.0 \%$ & 1 & $0.5 \%$ & 19 & $0.7 \%$ \\
\hline TW & 18 & $1.0 \%$ & 17 & $2.5 \%$ & 5 & $2.7 \%$ & 40 & $1.5 \%$ \\
\hline US & 8 & $0.5 \%$ & 2 & $0.3 \%$ & 2 & $1.1 \%$ & 12 & $0.5 \%$ \\
\hline Other & 18 & $1.0 \%$ & 6 & $0.9 \%$ & 9 & $4.8 \%$ & 33 & $1.3 \%$ \\
\hline Total & 1,719 & $100.0 \%$ & 692 & $100.0 \%$ & 188 & $100.0 \%$ & 2,599 & $100.0 \%$ \\
\hline
\end{tabular}

Notes: The sample consists of all patent infringement proceedings. The unit of observation is at the case level. In case of multiple patent holders or alleged infringers, the one closest to court is chosen. Category Other refers to countries with $\mathrm{N}<10$ in total. 
Table B-4: Estimation models for delaying events in infringement proceeding

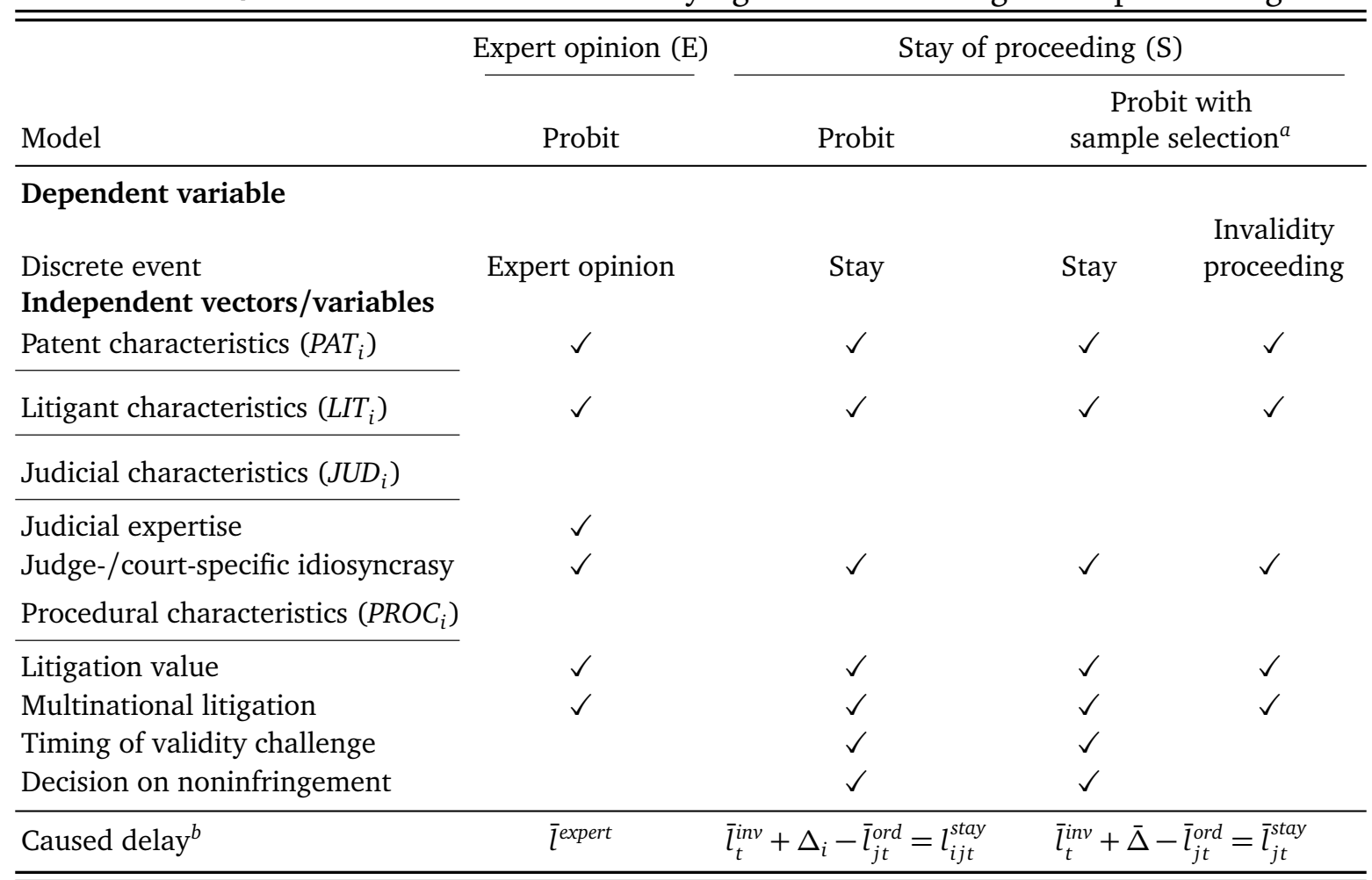

a For cases with no invalidity proceeding pending at time of court selection.

$b$ Ex ante likelihood of stay of proceeding predicted on basis of average delay of invalidity proceeding $\bar{\Delta}$ and average rate of decision on noninfringement (conditional on no settlement). Values used for the median lengths $\bar{l}$ can be found in Table B-5 in the Appendix. 


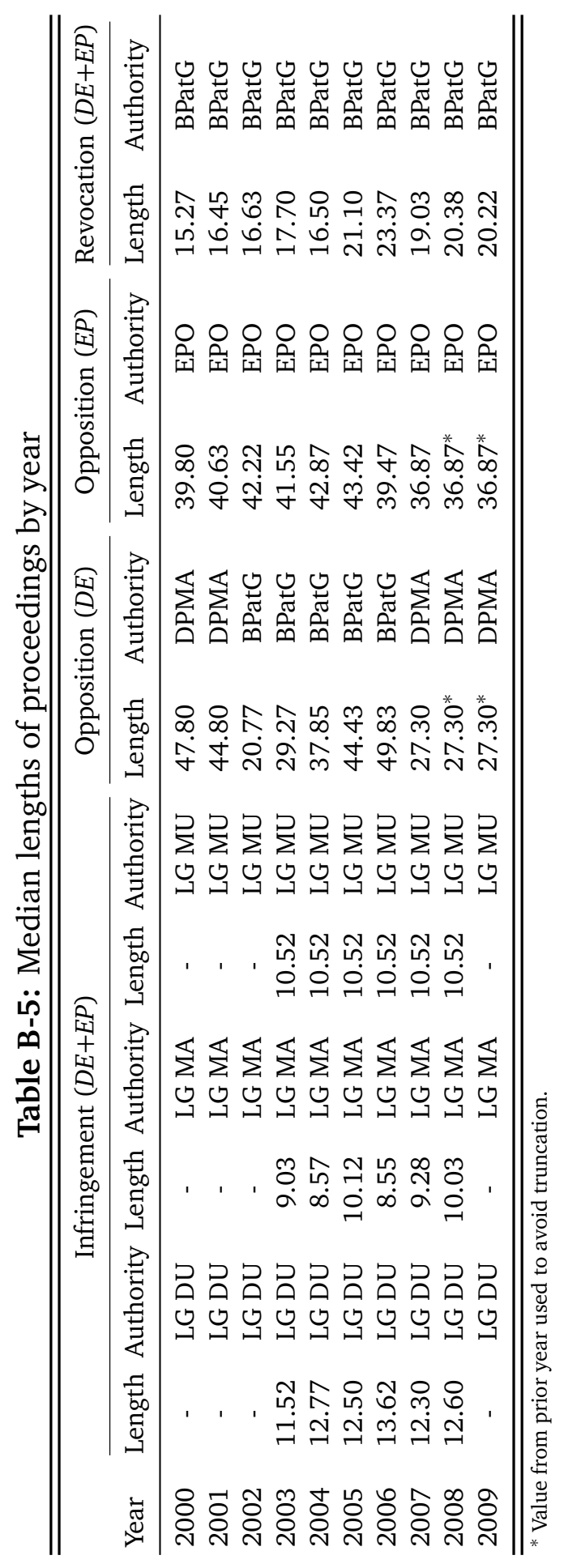

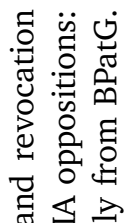

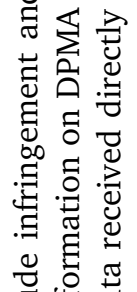
䆑要 শे 3.

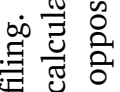
पै 芯芯 웅

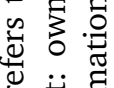
近 ฐँّ 舟豈 E 巡 을. 웡 鞄 苋富宁 象勘 สิ 峁 施: : 客言言离 . 동 유 预边 可 . ․ำ 㱐 过夆

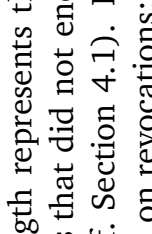

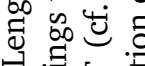

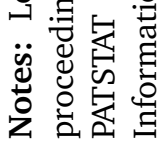


Table B-6: Groups of control variables

\begin{tabular}{ll}
\hline \hline Group name & Variables in group \\
\hline Patent characteristics & Dummy for PCT application \\
& Dummy for EP bundle patent \\
& Dummy for accelerated examination \\
& Size of DOCDB family \\
& Age of patent (in years) \\
& Age of patent (in years, squared) \\
& Number of IPC classes \\
& Number of inventors \\
& Number of patent forward citations (first 3 years) \\
& Number of patent literature references \\
& Number of non-patent literature references \\
\hline Invalidity history & Dummy for patent solidified in prior opposition proceeding \\
& Dummy for patent with prior revocation proceeding \\
& Dummy for patent solidified in prior revocation proceeding \\
\hline Litigant characteristics & Dummy for plaintiff NPE \\
& Dummy for plaintiff with top legal representative \\
& Dummies for plaintiff country (3) \\
& Dummies for plaintiff size (4) \\
& Dummy for defendant with top legal representative \\
& Dummies for defendant country (3) \\
& Dummies for defendant size (4) \\
\hline Year effects & Dummies for technology class (5) \\
\hline & Dummies for year of filing (6) \\
\hline
\end{tabular}


Table B-7: Alternative-specific conditional logit model results: court selection III

\begin{tabular}{|c|c|c|c|c|}
\hline Dependent variable: court & $\begin{array}{l}\text { (C9) } \\
\text { Defendant } \\
\text { European }\end{array}$ & $\begin{array}{c}\text { (C10) } \\
\text { Plaintiff } \\
\text { European }\end{array}$ & $\begin{array}{c}(\mathrm{C} 11) \\
\text { Defendant distance } \\
\geq 150 \mathrm{~km}\end{array}$ & $\begin{array}{c}\quad(\mathrm{C} 12) \\
\text { Plaintiff distance } \\
\geq 150 \mathrm{~km}\end{array}$ \\
\hline \multicolumn{5}{|l|}{ Alternative-specific variables } \\
\hline Expected length (in months) & $\begin{array}{c}0.020 \\
(0.037)\end{array}$ & $\begin{array}{c}-0.011 \\
(0.040)\end{array}$ & $\begin{array}{c}0.020 \\
(0.053)\end{array}$ & $\begin{array}{c}0.062 \\
(0.047)\end{array}$ \\
\hline Expected length $\times$ Market proximity & $\begin{array}{c}-0.088^{* *} \\
(0.040)\end{array}$ & $\begin{array}{r}-0.082^{*} \\
(0.044)\end{array}$ & $\begin{array}{c}-0.084 \\
(0.058)\end{array}$ & $\begin{array}{c}-0.106^{* *} \\
(0.051)\end{array}$ \\
\hline Plaintiff distance to court (in th $\mathrm{km}, \log$ ) & $\begin{array}{c}-0.662^{* * *} \\
(0.086)\end{array}$ & $\begin{array}{c}-0.689^{* * *} \\
(0.090)\end{array}$ & $\begin{array}{c}-0.705^{* * *} \\
(0.168)\end{array}$ & $\begin{array}{c}-1.058^{* * *} \\
(0.245)\end{array}$ \\
\hline Plaintiff distance to court $\times$ Plaintiff large & $\begin{array}{c}0.343^{* * *} \\
(0.108)\end{array}$ & $\begin{array}{c}0.387^{* * *} \\
(0.111)\end{array}$ & $\begin{array}{c}0.286 \\
(0.187)\end{array}$ & $\begin{array}{c}0.391 \\
(0.335)\end{array}$ \\
\hline Defendant distance to court (in th $\mathrm{km}, \log$ ) & $\begin{array}{c}-0.367^{* * *} \\
(0.070)\end{array}$ & $\begin{array}{c}-0.388^{* * *} \\
(0.077)\end{array}$ & $\begin{array}{c}-0.541^{* *} \\
(0.260)\end{array}$ & $\begin{array}{c}-0.413^{* * *} \\
(0.102)\end{array}$ \\
\hline Defendant distance to court $\times$ Plaintiff large & $\begin{array}{r}0.160^{*} \\
(0.095)\end{array}$ & $\begin{array}{r}0.196^{*} \\
(0.104)\end{array}$ & $\begin{array}{c}0.339 \\
(0.354)\end{array}$ & $\begin{array}{c}0.074 \\
(0.131)\end{array}$ \\
\hline \multicolumn{5}{|l|}{ Case-specific variables: LG Mannheim (MA) } \\
\hline Prior case at court (in last 3 years) & $\begin{array}{c}-0.044 \\
(0.167)\end{array}$ & $\begin{array}{c}0.169 \\
(0.161)\end{array}$ & $\begin{array}{c}0.300 \\
(0.218)\end{array}$ & $\begin{array}{c}-0.319 \\
(0.225)\end{array}$ \\
\hline Litigation value (in 100 th $€$ ) & $\begin{array}{c}-0.033^{* *} \\
(0.013)\end{array}$ & $\begin{array}{c}-0.035^{* *} \\
(0.016)\end{array}$ & $\begin{array}{c}-0.061^{* * *} \\
(0.017)\end{array}$ & $\begin{array}{r}-0.029^{*} \\
(0.016)\end{array}$ \\
\hline Market proximity & $\begin{array}{c}0.228 \\
(0.159)\end{array}$ & $\begin{array}{c}0.113 \\
(0.165)\end{array}$ & $\begin{array}{c}0.043 \\
(0.213)\end{array}$ & $\begin{array}{c}0.181 \\
(0.208)\end{array}$ \\
\hline \multicolumn{5}{|l|}{ Case-specific variables: LG Munich (MU) } \\
\hline Prior case at court (in last 3 years) & $\begin{array}{c}-1.032^{* *} \\
(0.423)\end{array}$ & $\begin{array}{c}-1.177^{* *} \\
(0.496)\end{array}$ & $\begin{array}{c}-0.687 \\
(0.609)\end{array}$ & $\begin{array}{r}-1.161^{*} \\
(0.623)\end{array}$ \\
\hline Litigation value (in 100 th $€$ ) & $\begin{array}{c}-0.086^{* *} \\
(0.039)\end{array}$ & $\begin{array}{c}-0.104^{* *} \\
(0.053)\end{array}$ & $\begin{array}{c}-0.083 \\
(0.051)\end{array}$ & $\begin{array}{r}-0.076^{*} \\
(0.042)\end{array}$ \\
\hline Market proximity & $\begin{array}{c}0.128 \\
(0.288)\end{array}$ & $\begin{array}{c}0.035 \\
(0.282)\end{array}$ & $\begin{array}{c}-0.281 \\
(0.390)\end{array}$ & $\begin{array}{c}0.151 \\
(0.366)\end{array}$ \\
\hline Litigant characteristics & Yes & Yes & Yes & Yes \\
\hline Technology effects & Yes & Yes & Yes & Yes \\
\hline Years & Yes & Yes & Yes & Yes \\
\hline Log likelihood & $-1,109.470$ & -996.459 & -561.175 & -669.443 \\
\hline Observations & 5,502 & 4,617 & 3,000 & 3,543 \\
\hline
\end{tabular}

Bootstrapped standard errors in parentheses

${ }^{*} p<0.10,{ }^{* *} p<0.05,{ }^{* * *} p<0.01$

Notes: The sample consists of all patent infringement proceedings without a (prior) request for a preliminary injunction. The unit of observation is at the case level. Base line regional court: LG Düsseldorf (DU). Control variables as stated in Table B-6. Bootstrapped standard errors with 200 iterations reported. 